\title{
EVIDENCIAS DE UN ENTERRAMIENTO RITUAL EN UN SECTOR RESIDENCIAL DE LA PARTE ALTA DE CARAL, VALLE DE SUPE
}

Arturo Noel Espinoza

\section{RESUMEN}

Se presenta los resultados preliminares de las investigaciones realizadas en uno de los recintos del Sector Residencial A, ubicado en la mitad alta del sitio arqueológico de Caral (3000-2000 a. C.) - Valle de Supe. Los datos describen el sucesivo enterramiento ritual de dicho recinto, correlacionados con la definición de las diferentes fases constructivas de los recintos adyacentes.

\section{ABSTRACT}

The preliminary results of the research done in one of the precinct of Residential Sector A, located in the middle high of the archaeological site of Caral (3000-2000 B.C.) - Supe Valley are presented. The data describe the successive ritual burial of that precinct, correlated with the definition of the different constructive phases of the contiguous precincts. 
L as evidencias obtenidas en el Recinto-1 (R-1), perteneciente al Módulo Arquitectónico $\mathrm{N}^{\circ} 2$ del Sector $\mathrm{A}$, indican enterramientos rituales que se dieron durante las diferentes fases constructivas. En general, la información comprende la definición de la secuencia constructiva y el reporte de los hallazgos materiales, concerniente a las "ofrendas".

Los datos permiten aproximarnos a la comprensión de la función que habría tenido el recinto excavado, el cual fue correlacionado con los recintos adyacentes (R-2, 3, 4 y 6); así como también nos permiten plantear hipótesis acerca del significado y el rol que las "ofrendas" descritas habrían cumplido dentro de la cosmovisión inserta en un sistema ideológico que tuvo la sociedad de Caral, en particular, y el Estado Prístino de Supe, en general, durante el período Arcaico Tardío (3000-2000 a. C.).

\section{UBICACIÓN DEL SITIO ARQUEO- LÓGICO}

Caral se encuentra ubicado en la margen izquierda del río Supe, provincia de Barranca, en la costa norcentral del Perú, cerca del poblado actual de Caral. A la altura del km 182 de la carretera Panamericana Norte, se presenta el desvío hacia el pueblo de Ámbar, desde donde se avanza aproximadamente $23 \mathrm{~km}$ hasta llegar a unos $350 \mathrm{msnm}$, en donde sobre una terraza aluvial, por encima del valle, se encuentra el sitio arqueológico de Caral (Shady 1997: 11).

\section{UBICACIÓN DEL SECTOR A}

En lo que respecta al Sector A (lugar donde se realizan las investigaciones), podemos indicar que éste se encuentra en la explanada de la terraza aluvial derecha de la quebrada por donde pasó un aluvión; dicho sector está emplazado en el espacio abierto más extenso de la ciudad, en cuyo entorno se erigieron las enormes estructuras piramidales (Lámina 1).

Ocupa un área de forma rectangular, con terrazas y muros de contención, levantados con bloques de piedra. Las excavaciones preliminares realizadas en temporadas anteriores, permiten distinguir en el interior espacios abiertos y subdivisiones, correspondientes al Módulo $\mathrm{N}^{\circ} 2$, el cual se encuentra ubicado de manera contigua al Este del Módulo $\mathrm{N}^{\circ} 1$, en la parte central del Sector A (Lámina 2).

$\mathrm{Al}$ igual que otros conjuntos arquitectóni$\cos$, éste también fue objeto de un enterramiento progresivo; además, muestra sucesivas remodelaciones.

\section{Estratigrafía del Recinto-1 (Módu- lo $\mathrm{N}^{\circ}$ 2)}

En principio, la definición del Recinto-1 fue hecha basándose en dos cateos:

El primer cateo (Foto 1), en forma de "L", tuvo un ancho que varía de 25 a $45 \mathrm{~cm}$ con una longitud de $1,80 \mathrm{~m}(\mathrm{~N}-\mathrm{S})$ y $2 \mathrm{~m}(\mathrm{E}-\mathrm{O})$.

El segundo cateo, de forma cuadrangular, mide entre 70 y $80 \mathrm{~cm}(\mathrm{E}-\mathrm{O})$ por $110 \mathrm{~cm}$ (N-S).

La secuencia estratigráfica obtenida en el Recinto-1 es la siguiente:

- Capa I:

Consistencia: Suelta. 


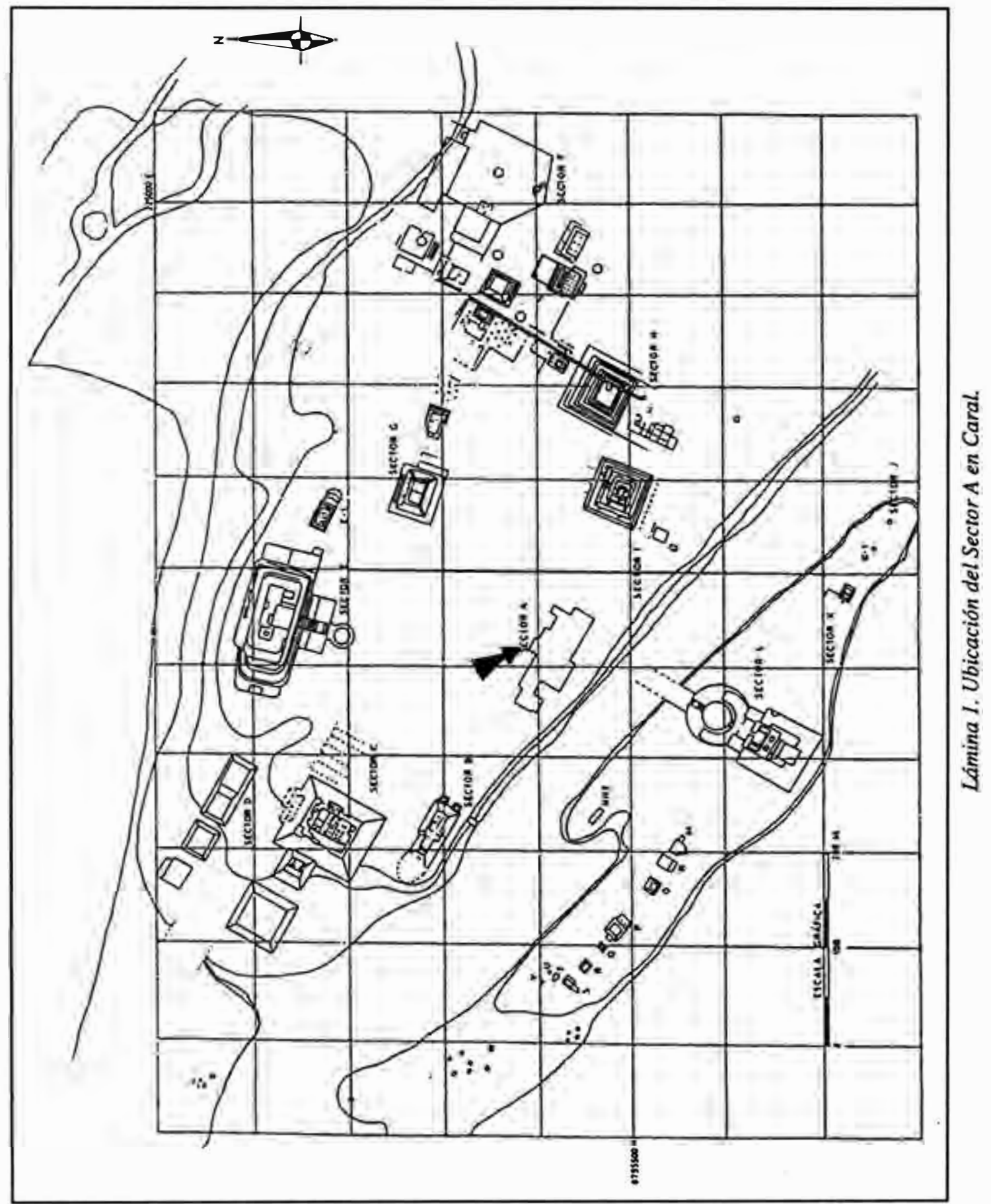




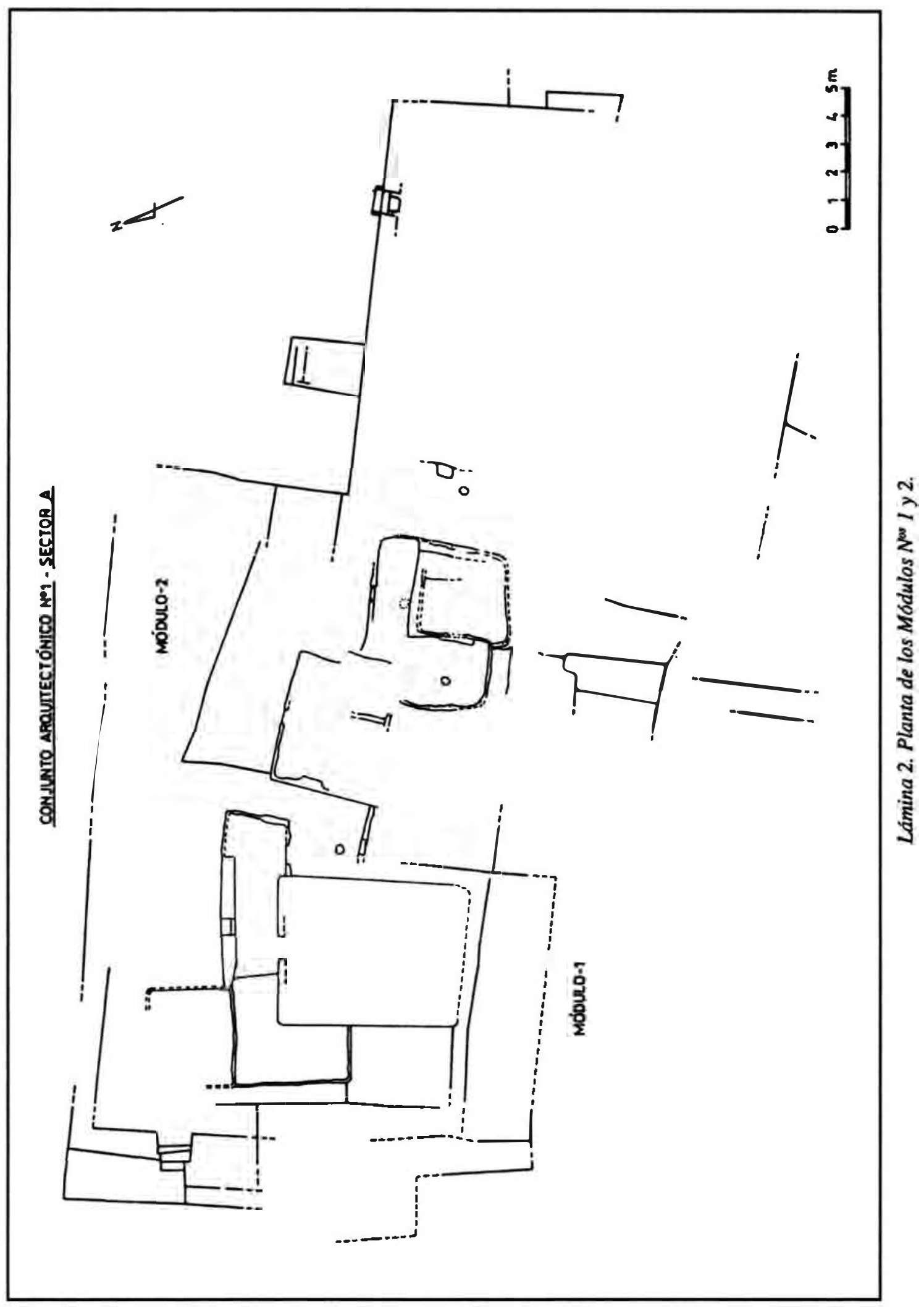




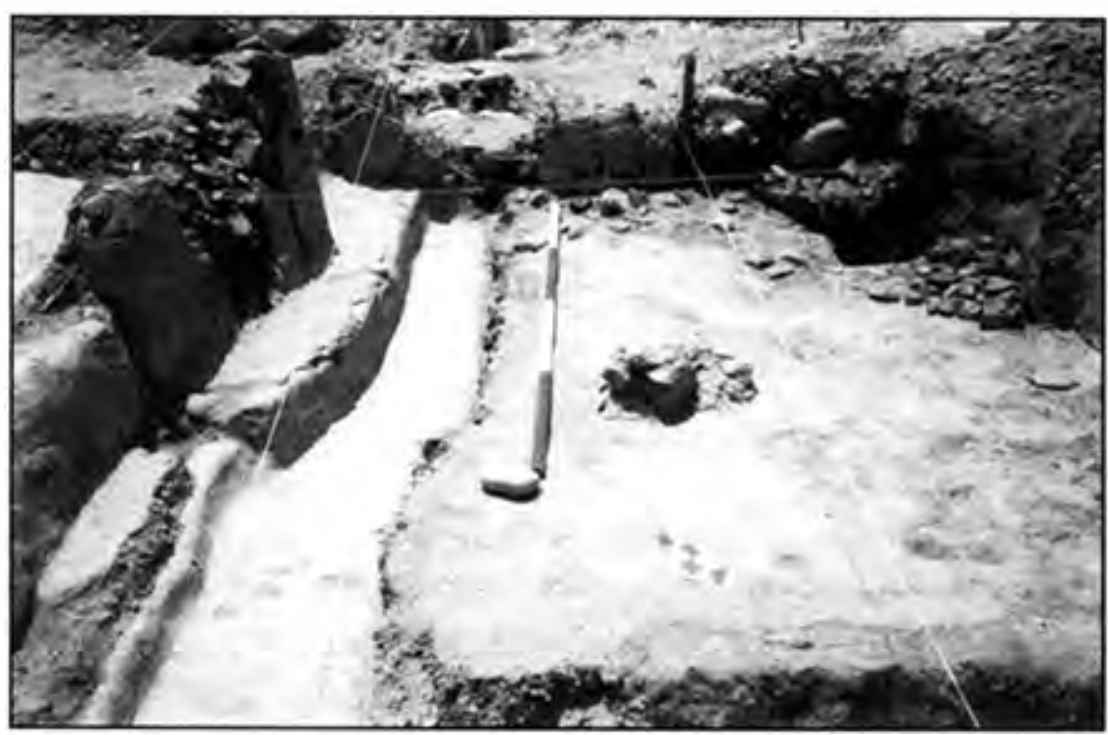

Foro 1. Vista norle del Recinto-I luego de retiradas las "shicras" y la ceniza. Se observa hacia la izquierda el Piso-2 en el cateo. 1 .

\section{Color: Beige.}

Composición': Tierra con poca arena y guijarros medianos y pequeños.

Espesor: $11 \mathrm{~cm}$ aproximadamente.

\section{- Capa II:}

Consistencia: Semicompacta.

Color: Beige claro.

Composición: Tierra con arcilla y cascajo pequeño y mediano en menor proporción.

Espesor: $2 \mathrm{~cm}$ aproximadamente.

\section{- Capa III:}

Consistencia: Suelta.

Color: Marrón claro.

Composición: Arena con tierra en menor proporción; presenta cascajo mediano y pequeño.

Espesor: $23 \mathrm{~cm}$ aproximadamente.

\footnotetext{
' La descripción en cuanto al tamaño de las piedras contenidas en las diferentes capas estratigráficas está en relación con los siguientes parámetros longitudinales, establecidos arbitrariamente:

Muy pequeño:

Pequeño:

De 1,5 a $3,5 \mathrm{~cm}$.

De 4 a $6,5 \mathrm{~cm}$.

Entre pequeño y mediano: De 7 a $10 \mathrm{~cm}$.

Mediano:

De 10,5 a $15 \mathrm{~cm}$.

Entre mediano y grande: De 15,5 a $19 \mathrm{~cm}$.

Grande:

Muy grande:
}

- Capa IV:

Consistencia: La superficie es semicompacta y el interior es suelto.

Color: Marrón oscuro.

Composición: Tierra con cascajo mediano, grumos de arcilla gris oscuro y amarillento. Se registró también material orgánico y lítico, además de restos de argamasa y enlucidos.

Espesor: Alcanza los $60 \mathrm{~cm}$.

\section{- Capa V:}

Consistencia: Suelta.

Color: Negro.

Composición: Ceniza y fragmentos de carbón pequeños. Presencia de material orgánico (fragmentos de "machas", "choros", semillas de "algodón", vértebras de "sardina", fragmentos de "mate").

Espesor: De 3 a $6 \mathrm{~cm}$ aproximadamente.

\section{- Piso - 1 (a)}

Presenta pintura beige; arcilla gris claro con inclusiones de piedra menuda ("ripio"). Espesor: $2 \mathrm{~cm}$.

- Piso - 1 (b)

Presenta enlucido amarillento; arcilla gris claro con inclusiones de "grama". Espesor: De 2 a $3 \mathrm{~cm}$. 
- Capa VI:

Consistencia: Suelta.

Color: Beige.

Composición: Tierra con cascajo muy pequeño y piedra menuda ("ripio") y algunas piedras angulares casi medianas. Se hallaron dos ofrendas de textiles quemados. Espesor: De 15 a $19 \mathrm{~cm}$.

\section{- Piso - 2}

Presenta pintura beige oscuro; enlucido gris claro y arcilla gris oscuro con inclusiones de "grama".

Espesor: De 1,5 a $2 \mathrm{~cm}$. Se halló un textil quemado colocado sobre el desnivel N-E. Además, se registró un hoyo, cerca a la esquina suroeste del recinto, cuyas dimensiones aproximadamente son de $45 \mathrm{~cm}(\mathrm{~N}-\mathrm{S})$ por $60 \mathrm{~cm}(\mathrm{E}-\mathrm{O})$ y una profundidad de 47 $\mathrm{cm}$. El hoyo contenía varias ofrendas.

\section{- Capa VII:}

Consistencia: Suelta.

Color: Marrón oscuro.

Composición: Tierra arcillosa con cascajo pequeño y algunos guijarros (redondeados $y$ angulares) de tamaño mediano con huellas de quema.
Presencia de material orgánico, tal como hojas, "algodón", "pacae" y ofrendas (de "sauce" con "algodón" y "choros").

Además, se halló un artefacto lítico circular, con agujero central (Lámina 3) y un fragmento de cuarzo.

Espesor: $44 \mathrm{~cm}$.

\section{- Capa VIII:}

Consistencia: Suelta.

Color: Beige.

Composición: Tierra con abundantes cantos rodados y piedras angulares de tamaño mediano y casi grandes.

Presencia de choros y restos de roedor (N. I.).

Espesor: De $10 \mathrm{~cm}$ hasta $48 \mathrm{~cm}$.

\section{- Capa IX:}

Consistencia: Compacta en parte de la superficie, a excepción de la esquina suroeste que rodea el poste, en una distancia de 40 $\mathrm{cm}$ aproximadamente. Bajo la superficie, la capa se torna suelta.

Color: La compactación es beige claro, para luego tornarse a un color que varía entre marrón claro a semioscuro.

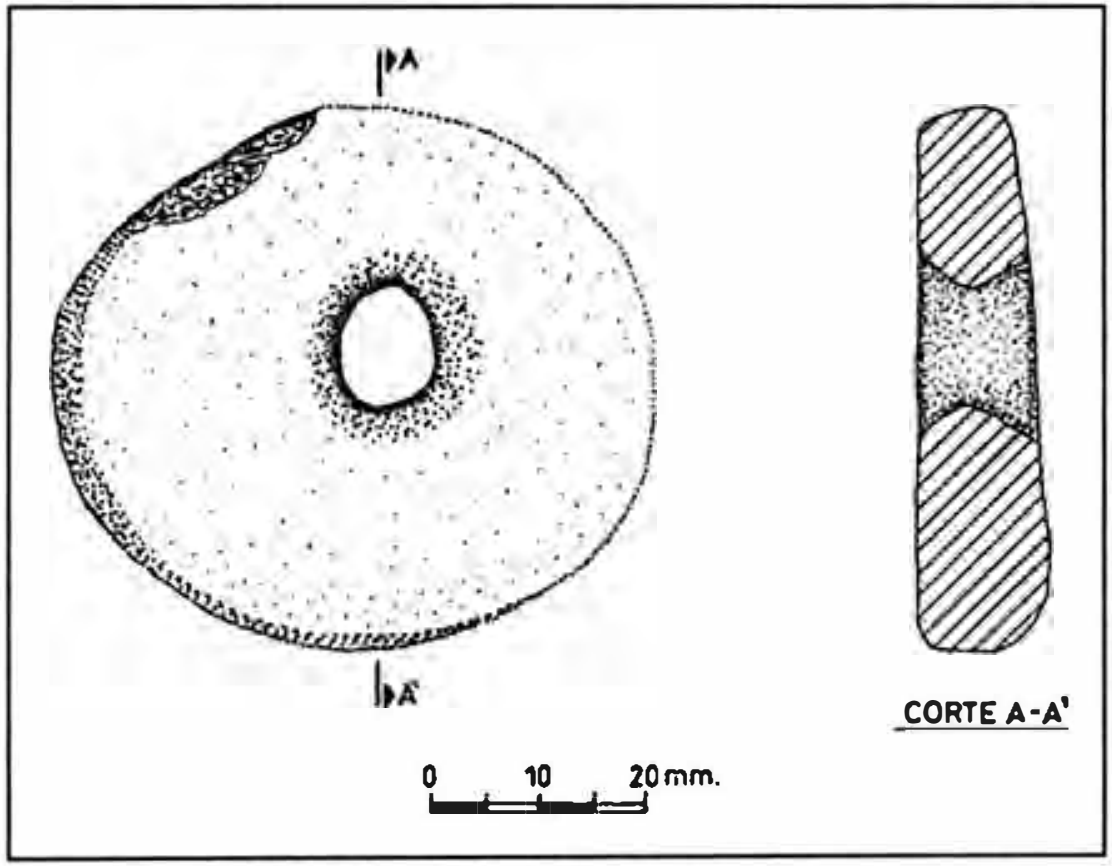

Lámina 3. Artefacto lítico hallado en la capa VII del Recinto-I. 
Composición: Tierra arcillosa con guijarros pequeños y casi medianos. Se halló pequeños "mechones" de cabello.

Espesor: Se excavó $20 \mathrm{~cm}$ aproximadamente, faltando aún profundizar.

\section{Contexto de los hallazgos más sig- nificativos}

En superficie de la Capa V: (Lámina 4)

Se hallaron diversos "manojos" de "sauce" cubiertos por 46 "shicras", en su mayoría de Cortaderia sp. (Foto 2).
Por otro lado, en la cuadrícula 4-N se hallaron debajo de una piedra angulosa (de 26 por 17 por $11 \mathrm{~cm}$ ), en el extremo sur, varias hojas y ramas de "sauce" y "paja", mientras que en el extremo norte se halló una soguilla de "junco"; en la parte central, además, se encontró una red anchovetera (?), la cual se extiende unos $19 \mathrm{~cm}$ de longitud por 9 $\mathrm{cm}$ de ancho.

También se observa plumas amarillas sujetadas a la red mediante hilos de algodón muy delgados; la red está asociada a hojas de "pacae" y vértebras de "anchoveta", "sardina" y fragmentos de "mate" (Foto 3 ).

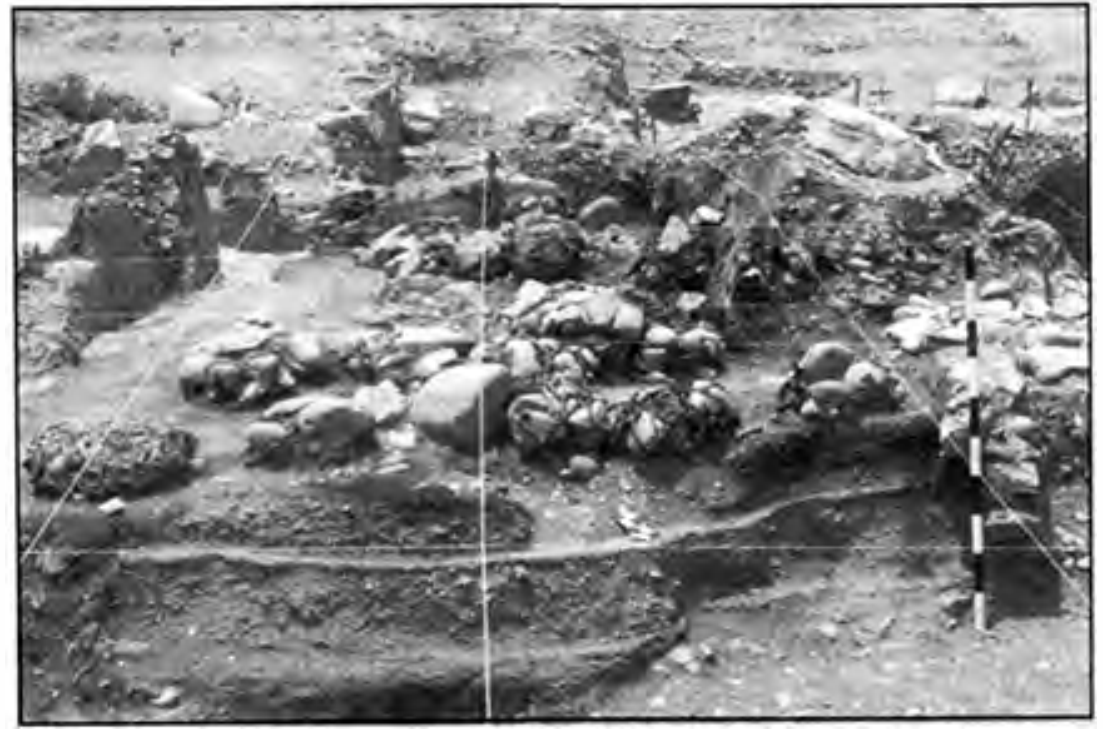

Foto 2. Vista norte del Recinto-3 y Recinto-I cubierto por "shicras".

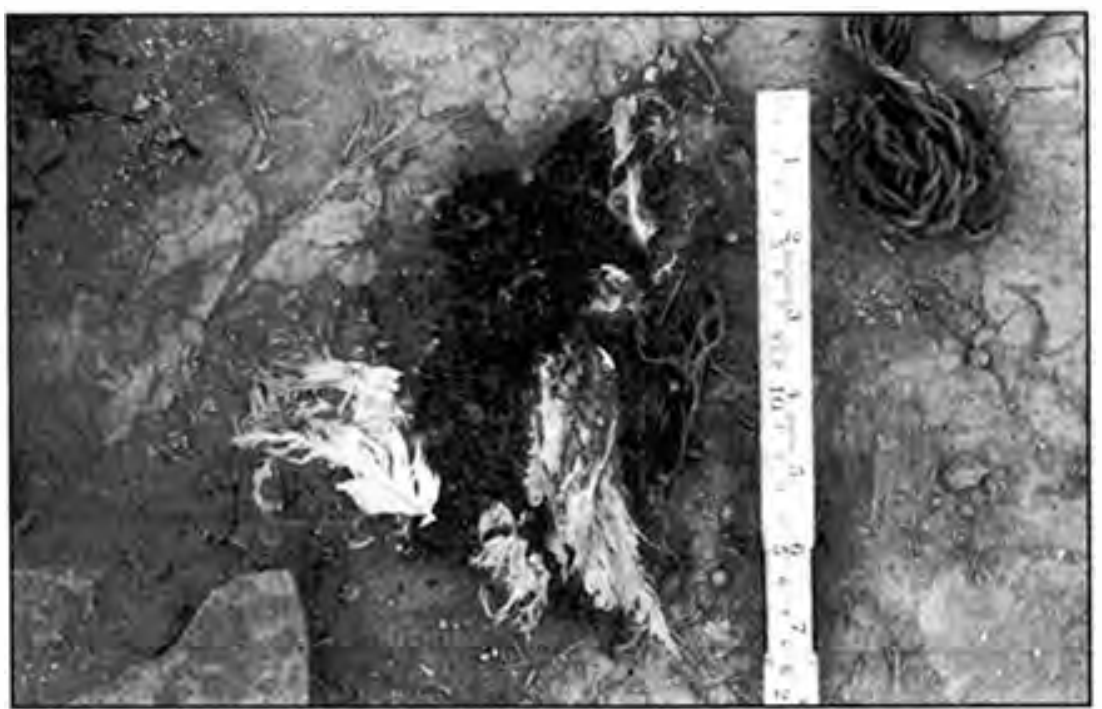

Foto 3. Detalle del textil con plumas amarillas que fue cubierto por una piedra angulosa, hallado sobre el Piso-l del Recinto-1. 


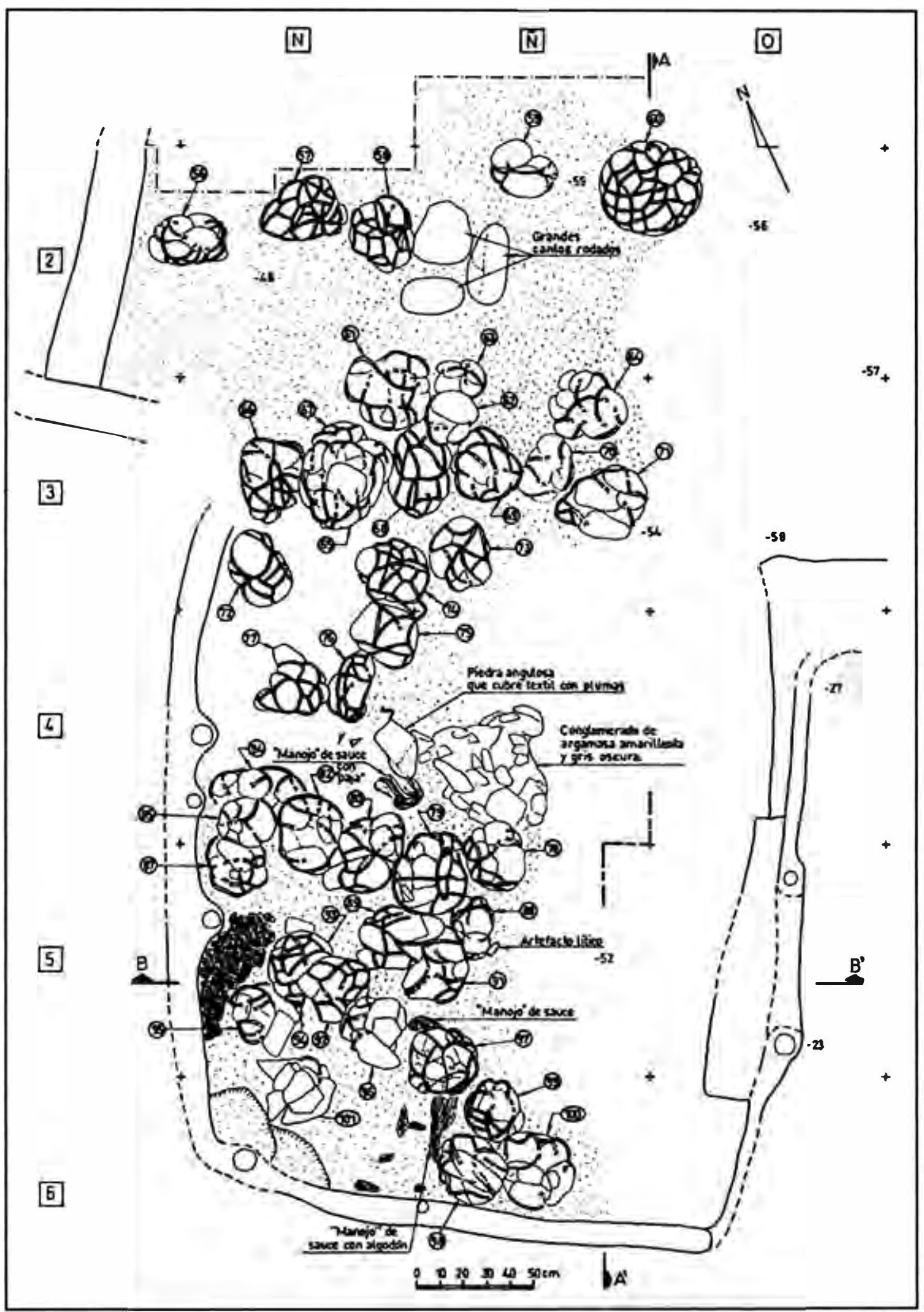

Lámina 4. Planta del Recinto-I, con ubicación de las "shicras" y los "hallazgos". 
En la Capa VI: (Lámina 5)

- "Ofrenda" $\mathrm{N}^{\circ} 1$ (Foto 4).- Ubicada en la cuadrícula 6-Ñ (Cateo 1).

Consiste en un textil quemado cubierto por una "armazón" de "sauce". La ofrenda mide $22 \mathrm{~cm}(\mathrm{E}-\mathrm{O})$ por 18 a $22 \mathrm{~cm}(\mathrm{~N}-\mathrm{S})$.

- "Ofrenda" $\mathrm{N}^{\circ} 2$ (Foto 5).- Ubicada entre las cuadrículas $4-\mathrm{N}$ y $4-\tilde{N}$.

Consiste en una especie de "armazón" hecha a partir de fibras de "junco" cruzadas conjuntamente con pequeñas ramas, debajo del cual se halló el textil quemado. La ofrenda mide $15 \mathrm{~cm}(\mathrm{E}-\mathrm{O})$ por $13 \mathrm{~cm}(\mathrm{~N}-\mathrm{S})$.

En superficie de desnivel noreste del Piso 2: (Foto 6)

Se halló en la cuadrícula 3-O, un fragmento de textil entrelazado quemado colocado sobre el desnivel N-E del Recinto-1.

En hoyo de Piso -2: (Lámina 5)

Ubicado en la cuadrícula 5-N. La ruptura del hoyo mide $45 \mathrm{~cm}(\mathrm{~N}-\mathrm{S})$ por $60 \mathrm{~cm}$ (EO), en la cual, hacia el oeste, se colocó un "manojo" de "sauce" cubriendo una valva de "choro morado".

Hacia el noreste se colocaron hojas (N. I.) y hacia el sur se depositó una estera (de 30 $\mathrm{cm}$ de longitud por $21 \mathrm{~cm}$ de ancho), sobre la cual se halló un fragmento de "mate" cortado en forma circular, de 4 a $5 \mathrm{~cm}$ de diámetro y un orificio central de $5 \mathrm{~mm}$ de diámetro (Foto 7).

Debajo de la estera se registró un fragmento textil de algodón entrelazado, sobre el cual, al parecer, vertieron líquido con barro gris oscuro, lo que originó su endurecimiento; se ubica a lo largo del extremo sur de la ruptura del piso.
Luego se presenta una compactación de argamasa beige de 1,5 a $2 \mathrm{~cm}$ de espesor, la cual cubre otras ofrendas: Un "mate" con cuello de botella, que estaba fragmentado, cubierto en gran medida por un "apelmazado" (de $12 \mathrm{~cm} \mathrm{~N}-\mathrm{S}$ por $17 \mathrm{~cm} \mathrm{E-O)} \mathrm{de} \mathrm{ra-}$ mas delgadas de "sauce" que presenta en superficie algunas vértebras de "anchoveta". Debajo del "mate" se halló un fragmento de rama de "caña brava" (de 11,5 cm de longitud aproximadamente), y hacia el noreste del hoyo se registró un "manojo" de ramas de "molle".

\section{En la Capa VII:}

Se halló, a $18 \mathrm{~cm}$ aproximadamente de distancia del Piso-2, una "ofrenda múltiple" colocada sobre piedras de granodiorita de tamaño grande, constituida por 6 elementos:

Elemento 1: "Manojo" de "sauce", de $25 \mathrm{~cm}$ de longitud; debajo se halló "algodón" y hojas (N. I.).

Elemento 2: "Manojo" de "sauce", de $27 \mathrm{~cm}$ de longitud.

Elemento 3: "Manojo" de "sauce", de $20 \mathrm{~cm}$ de longitud, asociado a un poco de "algodón".

Elemento 4: Constituido por "choros zapatos", algunos colocados uno sobre otro, formando conjuntos de 2, 3 y 4 valvas, mientras que otros están sueltos; se observa, además, que los mayores presentan manchas de pigmento de color beige.

Elemento 5: "Manojo" de "sauce", de $11 \mathrm{~cm}$ de longitud, atado con fibra de "junco".

Elemento 6: "Manojo" de "sauce", colocado debajo del Elemento 5 y sobre un bloque grande de granodiorita; no está bien conservado y se encuentra asociado a un fragmento de cuarzo y a un poco de "paja". 


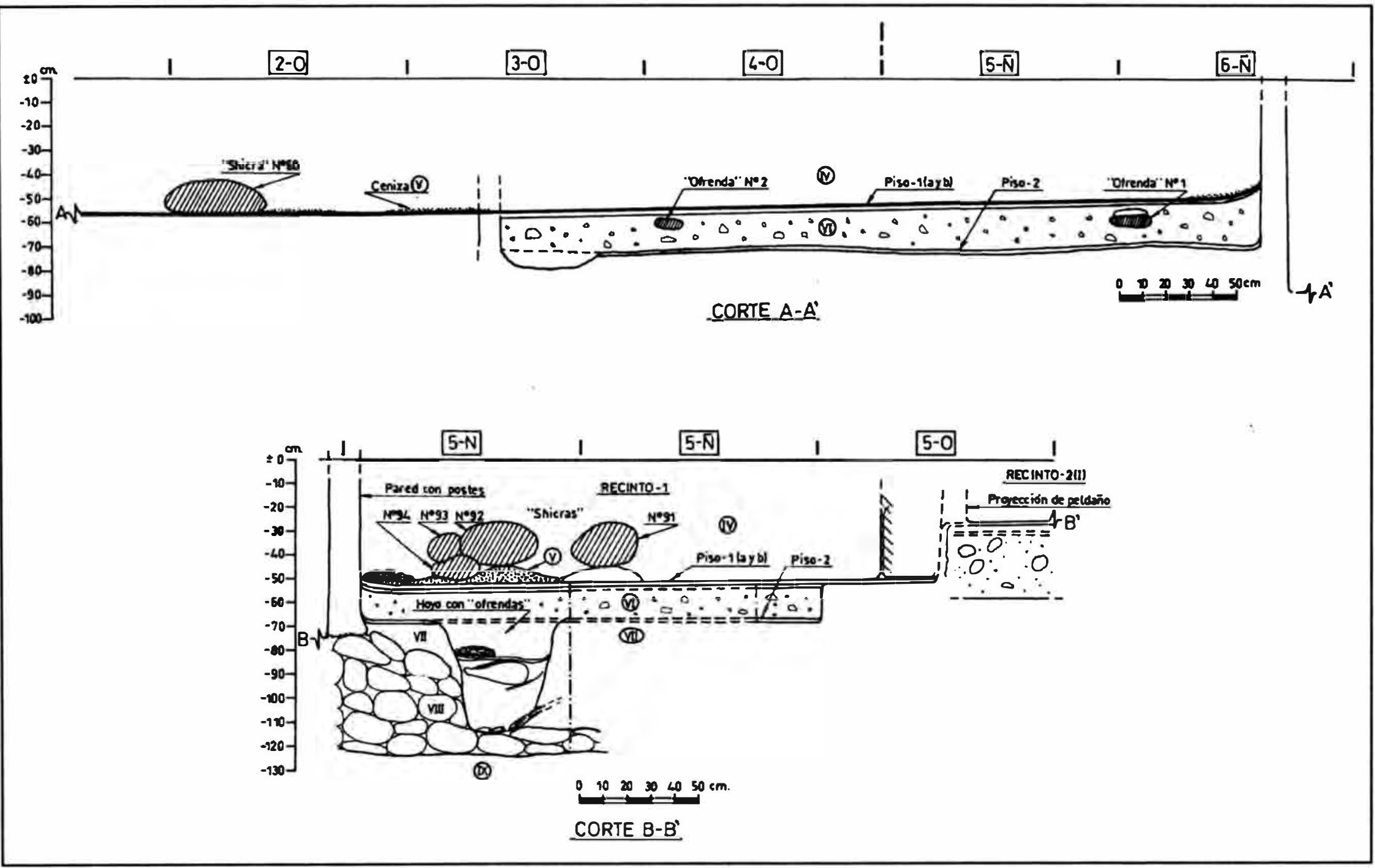

Lámina 5. Cortes estratigráficos $A-A^{\prime}$ y $B-B^{\prime}$ del Recinto-1. 


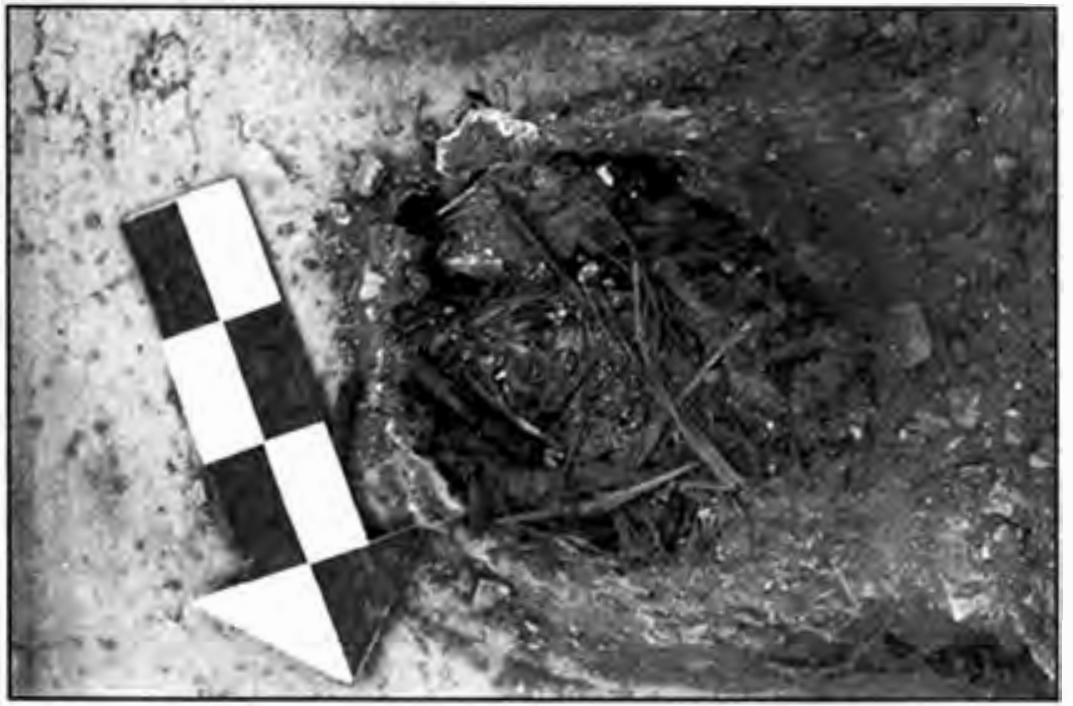

Foto 4. Detalle de la "ofrenda No I": Texril entrelazado quemado, con fibras vegetales (ramas de "sauce" y "carricillos"). Debajo del Piso-I del Recinto-1.

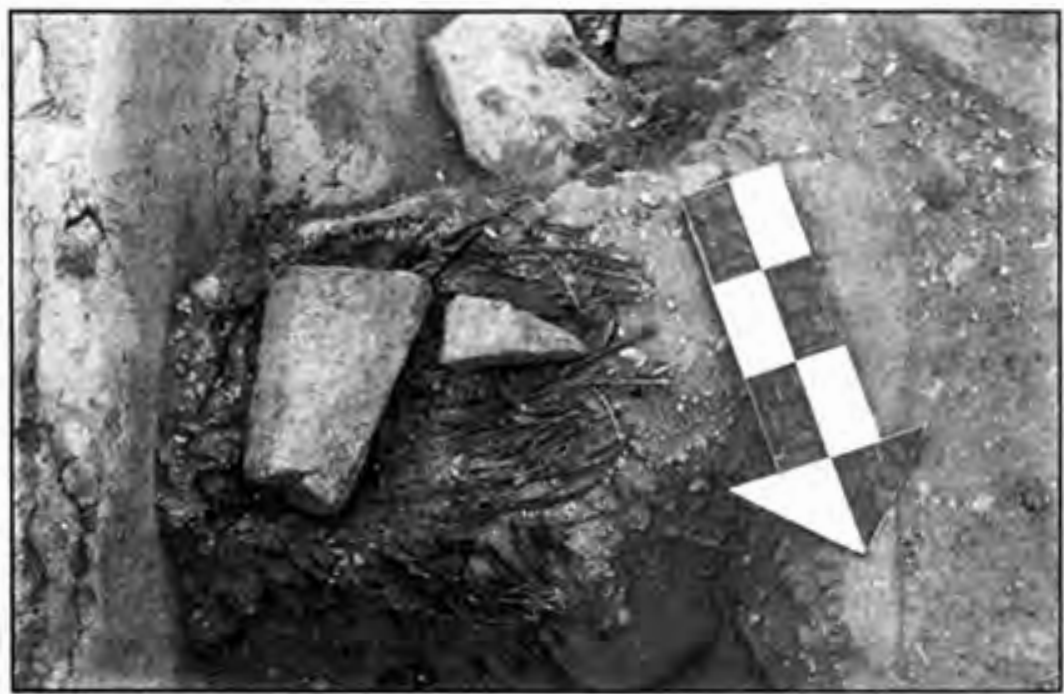

Foto 5. Detalle de la "ofrenda $N^{\circ} 2$ ": Textil entrelazado quemado, con fibra de "sauce" y laja de piedra cubriéndola. Debajo del Piso-I del Recinto-1.

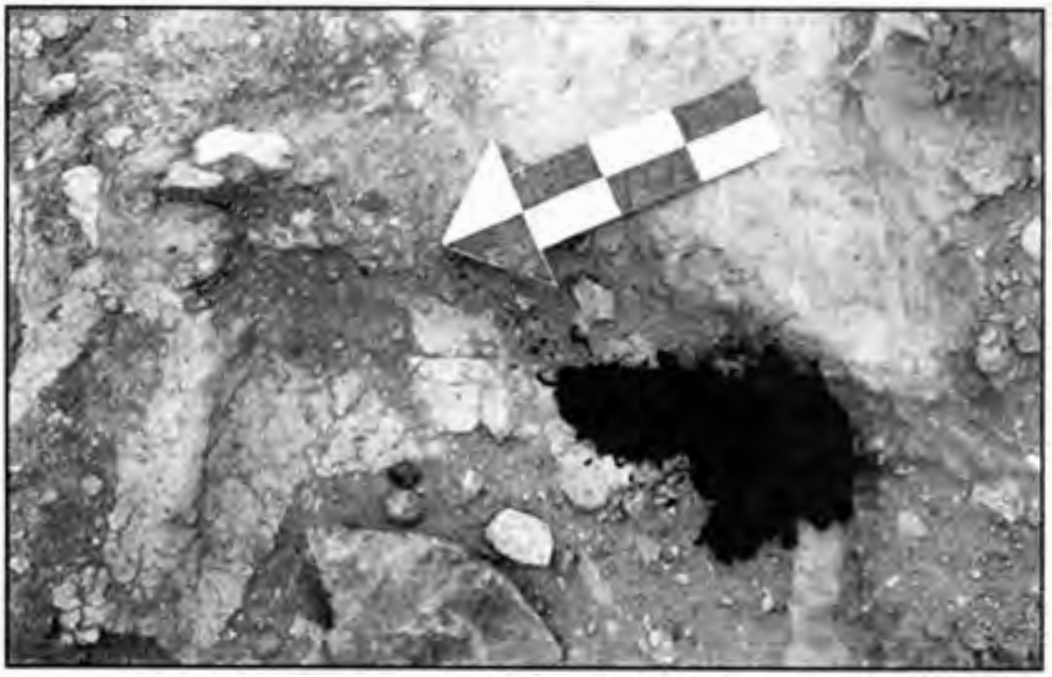

Foto 6. Detalle del textil entrelazado quemado, sobre un desnivel en la esquina noreste del Recinto-I. Debajo del Piso-l. 


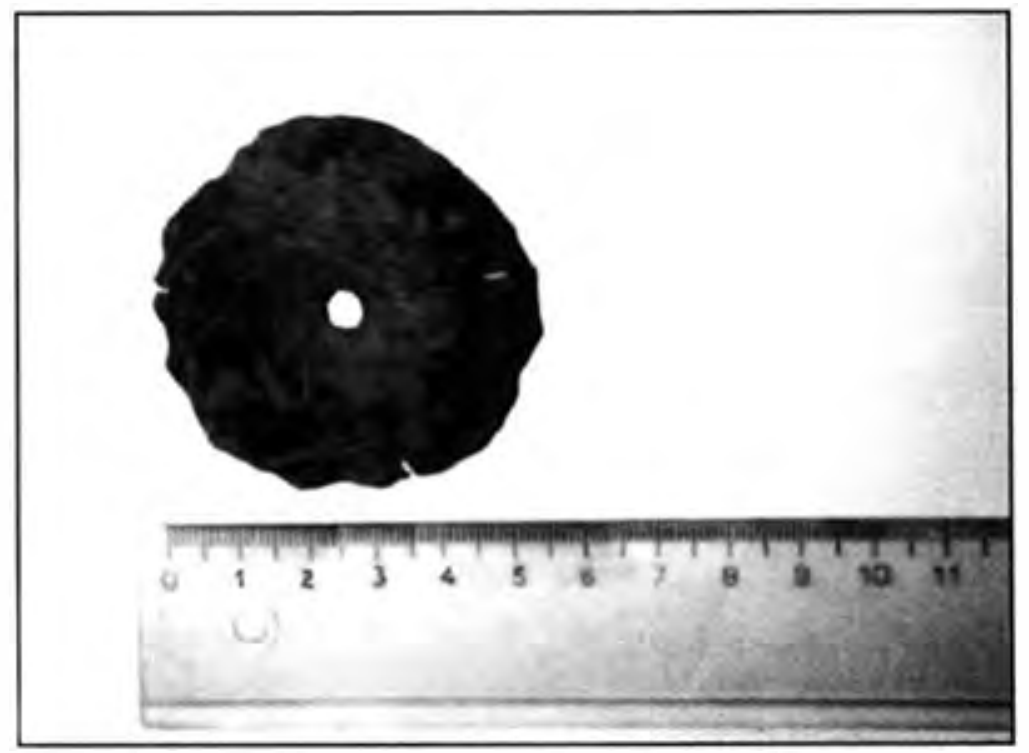

Foto 7. Fragmento de "mate" cortado en forma circular, con un pequeño orificio central. Hallado en el interior del hoyo del Piso-2.

\section{Secuencia constructiva}

Son ocho (8) las fases constructivas establecidas preliminarmente. Se ha tenido en cuenta, para la definición de ellas, principalmente, los siguientes tres criterios:

- Secuencia estratigráfica de los elementos arquitectónicos.

- Material y técnica constructiva empleada.

- Probable funcionalidad.

\section{- FASE I (Lámina 6)}

Sobre un relleno (capa VII) que contenía "ofrendas" de "manojos" de "sauce" se construyó el Recinto-1 (R-1), de forma cuadrangular (de 3,20 por $1,95 \mathrm{~m}$ ), delimitado por una pared de $1,70 \mathrm{~m}$ de altura aproximadamente, que presenta argamasa gris oscura, enlucida con arcilla amarillenta y pintura beige, construida sobre la base de una estructura interna compuesta por un reticulado de "carrizos" y "caña brava" a la cual se le añade cada 50 a $60 \mathrm{~cm}$ un poste de "sauce" o "guarango", todo ello sujetado con soguillas de "junco". Dicho recinto se comunicaba con un espacio ubicado hacia el este, a través de un pequeño desnivel de $14 \mathrm{~cm}$ de altura y es sobre este espacio que se halló restos de consumo de "anchoveta".

\section{- FASE II (Lámina 7)}

Durante la fase constructiva II, son cuatro los recintos interrelacionados:

Un recinto ubicado hacia el norte, denominado Recinto-4 (R-4), de forma rectangular, el cual presenta un vano de acceso de 42 $\mathrm{cm}$.

Este recinto está comunicado directamente con el Recinto-3 (R-3), hacia el oeste, el cual corresponde a un espacio cuadrangular de acceso previo al Recinto-1 (R-1), el cual presenta básicamente las dimensiones observadas durante la Fase I, salvo por el agregado de un desnivel ubicado hacia el este, que cubrió el desnivel anterior; conformándose así un recinto de piso hundido que se comunicaba, hacia el este, con dos recintos cuadrangulares: R-2 (I) y R2 (II).

El Recinto-2 (I), ubicado hacia el sur, mide $2,40 \mathrm{~m}$ de longitud norte-sur por $2 \mathrm{~m}$ de 


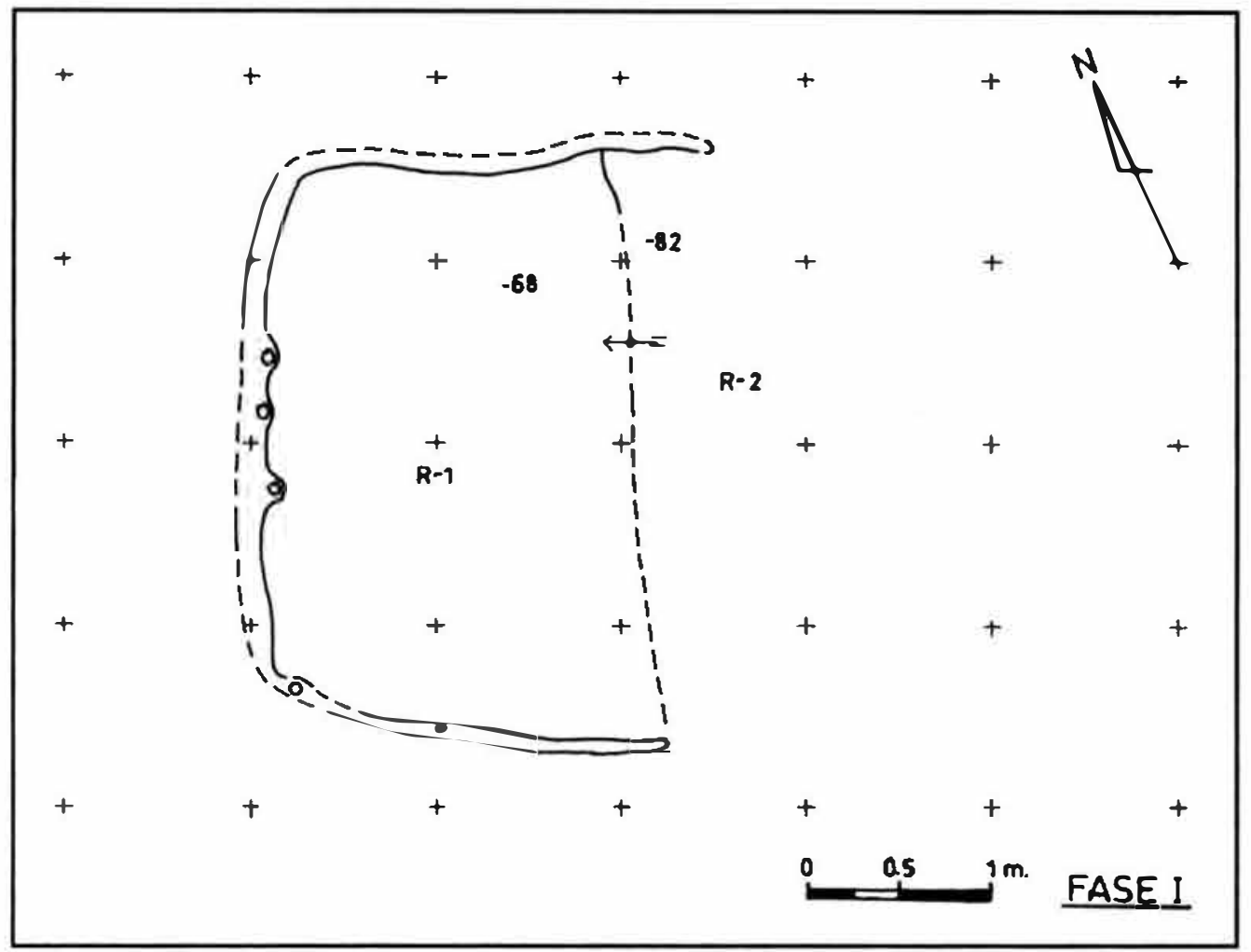

Lámina 6. Planta de la Fase I-Módulo $N^{\circ} 2$ (Sector A).

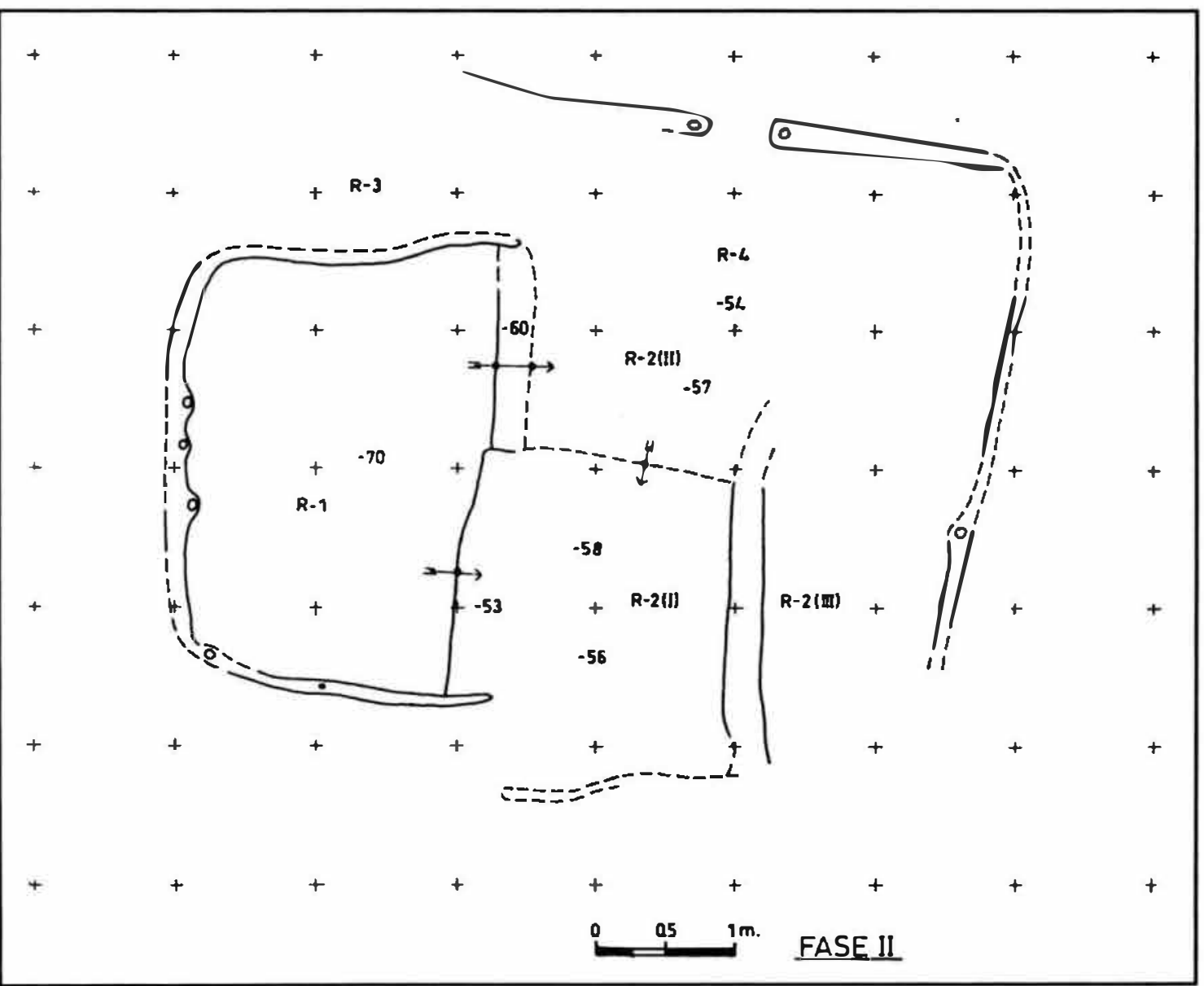

Lámina 7. Planta de la Fase II - Módulo $N^{\circ} 2$ (Sector A). 
longitud este-oeste. Presenta en el vértice suroeste un vano por el que se habrían retirado aquellas personas que previamente se congregaron en el Recinto-1 (R-1).

El Recinto-2 (II), ubicado hacia el norte, no se presenta bien definido; es probable que se haya comunicado con un tercer recinto [R-2 (III)], de más de $2,70 \mathrm{~m}$ de longitud norte-sur y $1,50 \mathrm{~m}$ de longitud esteoeste.

\section{- FASE III (Lámina 8)}

Durante esta fase se construye un nuevo vano de acceso, de $62 \mathrm{~cm}$ aproximadamente, al norte del Recinto-1, lo cual le da mayor restricción a su ingreso.

Por otro lado, se establece una separación de funciones por la división dada entre el Recinto-2 (II) y los recintos 1 y 2 (I) mediante la construcción de una pared delgada en forma de "L" con postes internos.

Y finalmente se elabora un fogón de 30 cm de diámetro, en la parte central del espacio constituido por la unión del Recinto-4 y el Recinto-2 (II), cuya longitud norte-sur es de $2,45 \mathrm{~m}$, por $2,60 \mathrm{~m}$ de longitud este-oeste.

El Recinto-1 y el Recinto-2 (I) pudieron haber cumplido una función habitacional, ya que la actividad ceremonial/ritual se estaría dando en el espacio, bastante amplio, con fogón central, conformado por la unión del Recinto-2 (II) y el Recinto-4.

- FASE IV (Lámina 9)

Durante esta fase constructiva la actividad ceremonial/ritual que se realizaba en el espacio comprendido entre el Recinto-2 (II) y el Recinto-4 es trasladada hacia el Recinto-1.
El Recinto-1 se convierte en el recinto más importante de este conjunto, puesto que en la parte central de este recinto se elabora un fogón de $28 \mathrm{~cm}$ de diámetro, concentrándose en este espacio la actividad ceremonial/ ritual.

Para cubrir el R-1 y construir luego el piso1 con fogón central, se hizo previamente un hoyo, en el piso-2, muy cerca de la esquina suroeste, el que contenía "ofrendas" (un "mate" con cuello de botella, "choros", "manojos" de "sauce", entre otros elementos); seguidamente, el piso-2 fue cubierto por una capa (capa VI) de tierra con cascajo muy pequeño, piedra menuda ("ripio") y algunas piedras angulares casi medianas; en ella se halló tres "ofrendas", dos de ellas ("ofrenda" $\mathrm{N}^{\circ} 1$ y $\mathrm{N}^{\circ} 2$ ) muy cerca de los desniveles ubicados al este y la tercera sobre el desnivel norte.

Por otro lado, el fogón ubicado en el espacio dado por el Recinto-2 (II) y el Recinto4 durante la fase anterior, fue sellado para dar paso a la construcción de una pared de $10 \mathrm{~cm}$ de espesor dispuesta en sentido esteoeste, adosada a la pared en forma de " $L$ " (hecha con una técnica similar, de armazón interno), conformándose así una delimitación del Recinto-2 (II) de forma rectangular, con una longitud norte-sur de 90 $\mathrm{cm}$ por más de $1,60 \mathrm{~m}$ de longitud esteoste.

Finalmente, hacia el este se habría conformado un nuevo recinto de $2,10 \mathrm{~m}$ de longitud norte-sur por $2,25 \mathrm{~m}$ de longitud esteoeste.

De esta forma el Recinto- 4 se convertiría en una especie de antesala, a partir de la cual las personas podrían acceder, por el oeste, hacia el espacio o recinto ceremonial y hacia el este, a dos recintos: R-2 (II) y R-2 (III) los cuales pudieron haber cumplido una función habitacional. 


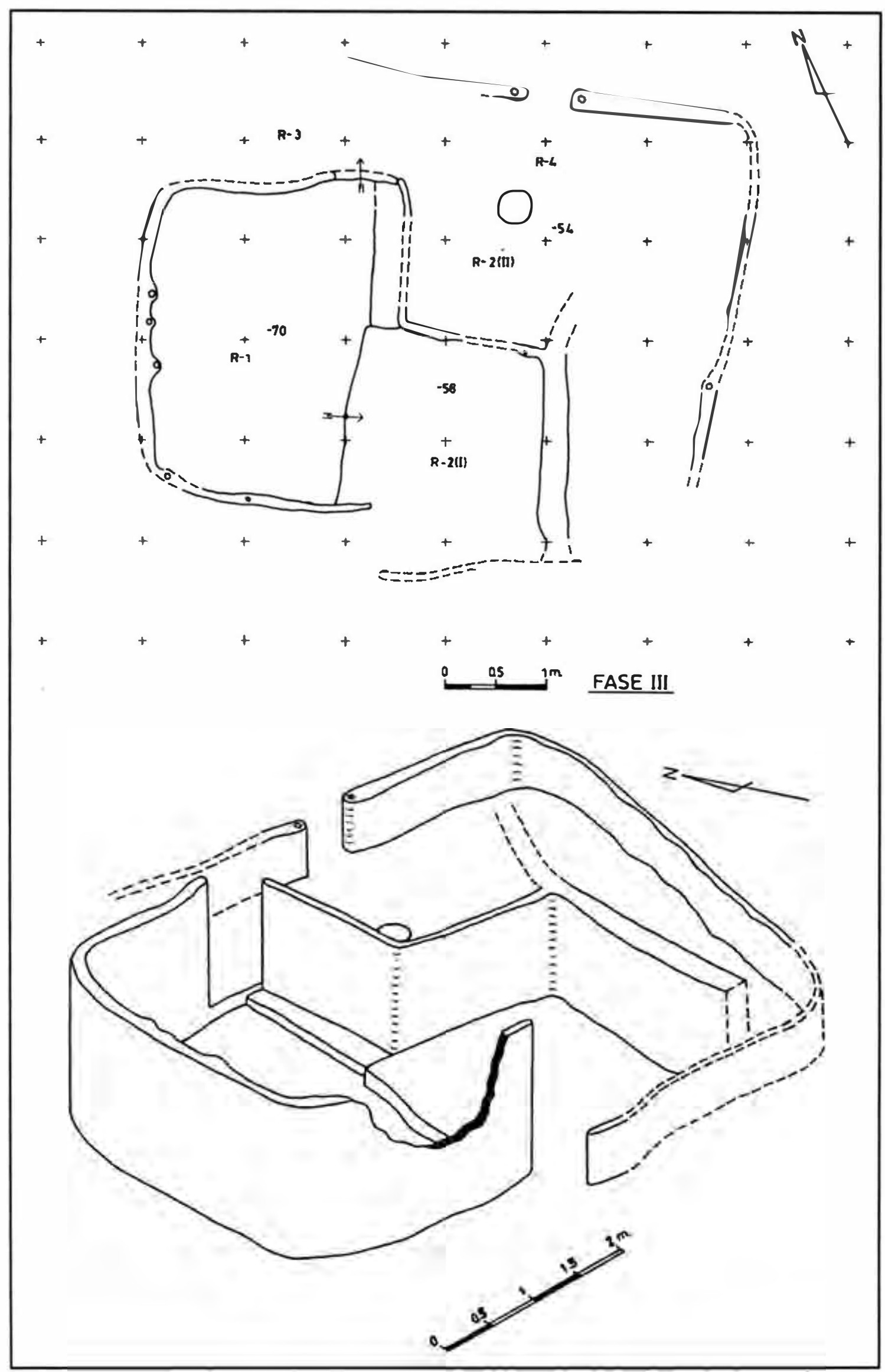

Lámina 8. Planta e isometria de la Fase III - Módulo $N^{\circ} 2$ (Sector A). 


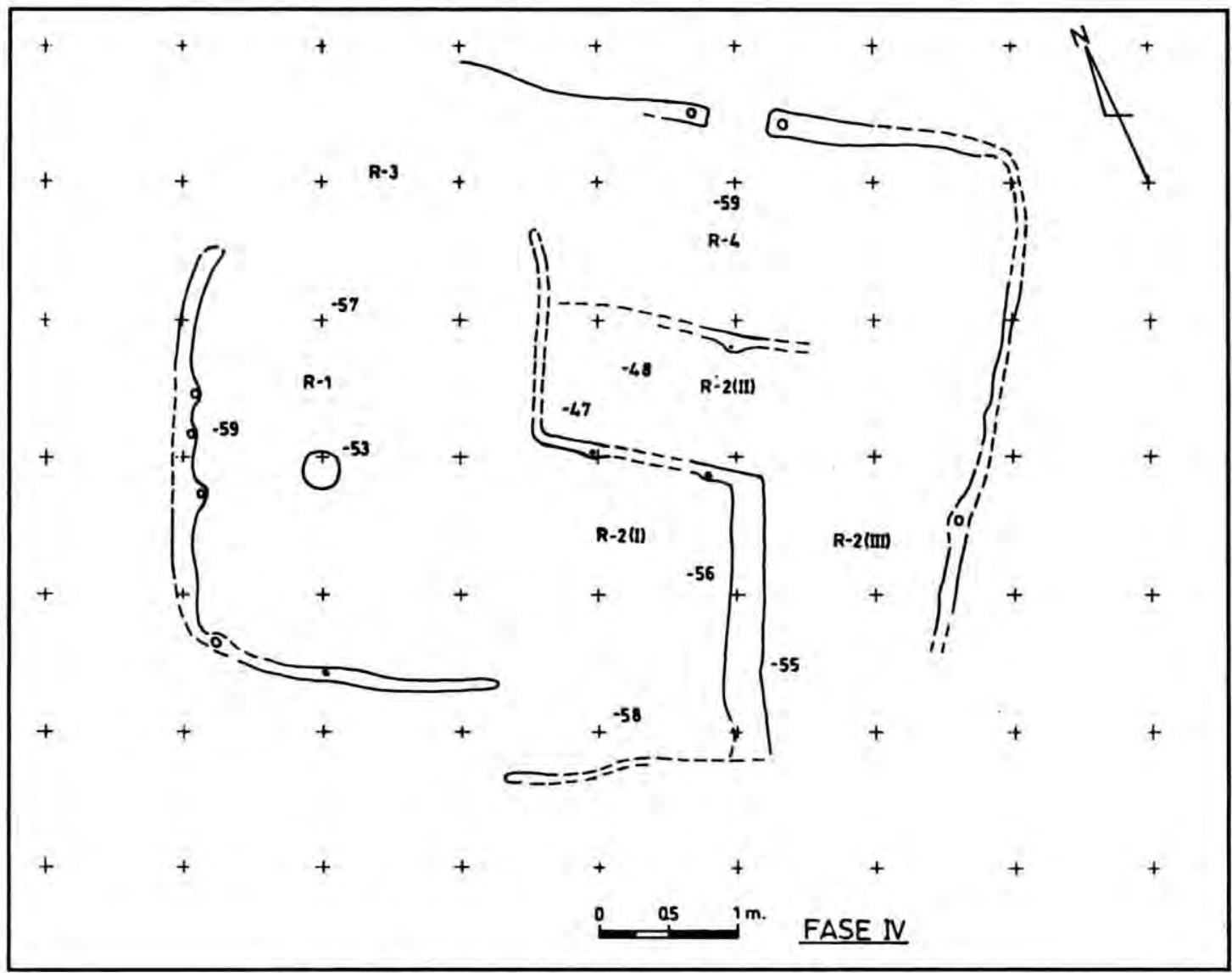

Lámina 9. Planta de la Fase IV - Módulo $N^{\circ} 2$ (Sector A).

\section{- FASE V (Lámina 10)}

Se restringe de forma muy marcada el acceso hacia el Recinto-2 (II) y al Recinto-2 (III) mediante un vano de casi $40 \mathrm{~cm}$.

A la vez, se construyen muros bajos de piedra que delimitan nuevamente el Recinto-2 (II), llegando a alcanzar una longitud de 3 $\mathrm{m} y$ un ancho de $1 \mathrm{~m}$.

Este recinto seguiría guardando una relación directa con el Recinto-2 (III) ubicado hacia el sureste.

Por otro lado, se clausura, con un muro de piedras, el acceso ubicado en el vértice suroeste del Recinto-2 (I).

De esta forma se estaría evitando una circulación fluida de ingreso y salida a través del espacio ceremonial del Recinto-1.
- FASE VI (Lámina 11)

La fase constructiva VI constituye un momento en el cual la actividad ceremonial/ritual se diversifica en dos recintos: R-1 y R-6.

El acceso principal a este conjunto de recintos continúa siendo por el lado norte del Recinto-4, a partir del cual se podía ingresar, hacia el oeste, sin mayores restricciones, al Recinto- 1 , y por el este, a través de un desnivel, al Recinto-6.

Desde el Recinto-1 se puede ingresar, pero de forma restringida, a través de un vano elevado hacia el Recinto-2, el cual constituye una nueva estructura, construida sobre los antiguos Recintos-2 (II) y 2 (III), los que fueron cubiertos por una capa de tierra y guijarros de diverso tamaño. Este nuevo recinto ( $R-2)$ estuvo delimitado por una pared de "quincha". 


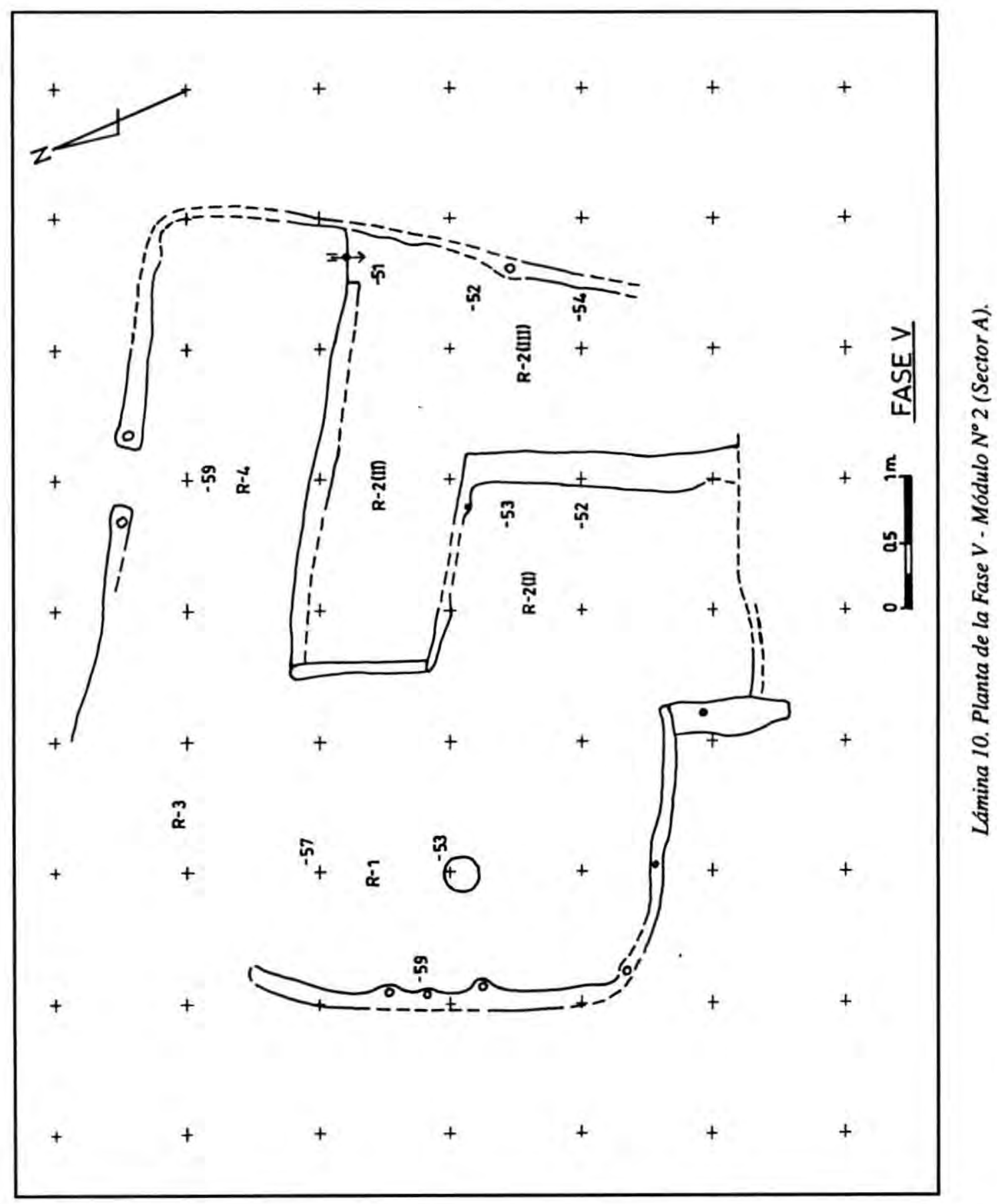




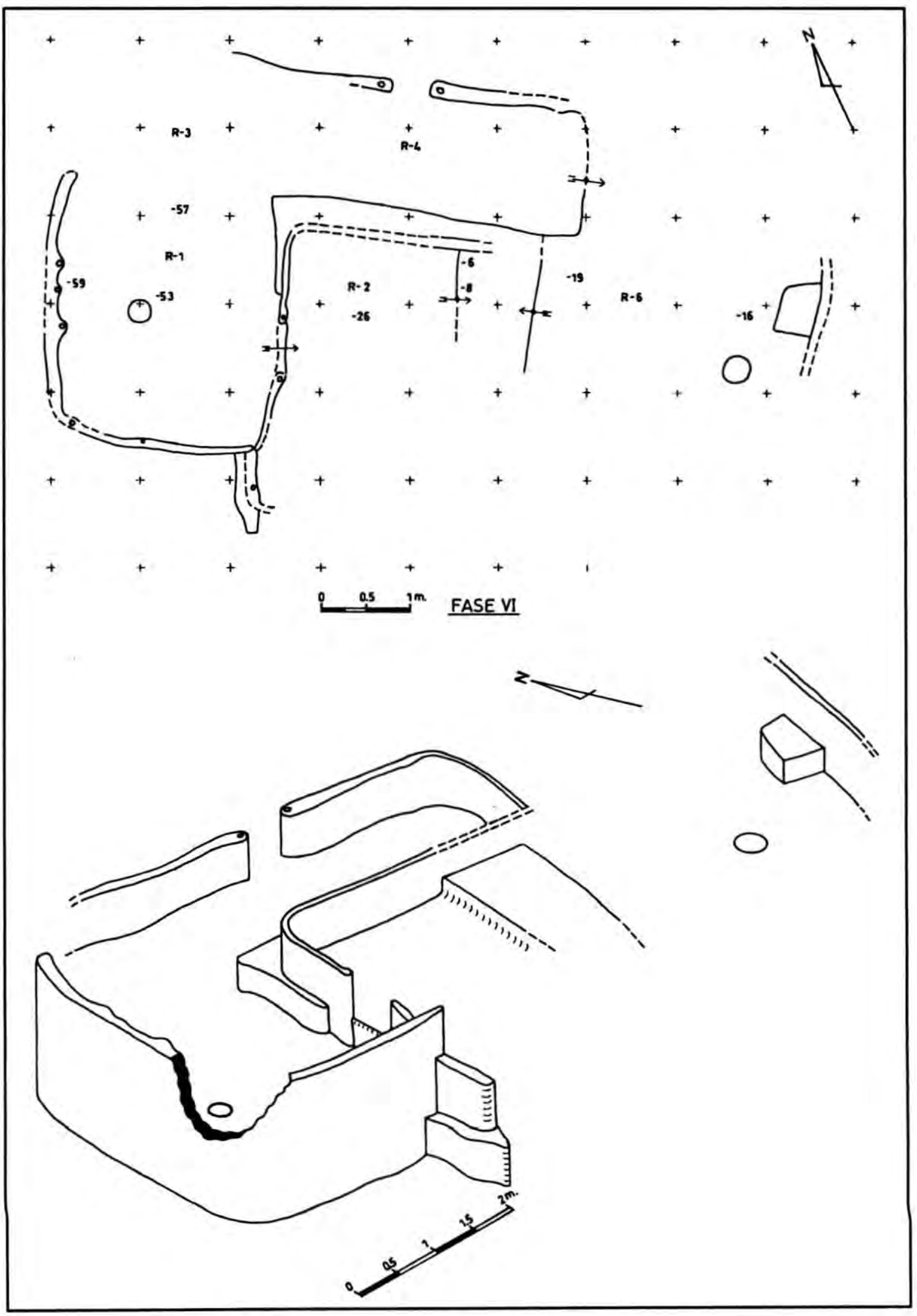

Lámina 11. Planta e isometría de la Fase VI - Módulo $N^{\circ} 2$ (Sector A). 
A continuación, hacia el lado este del Recinto-2 se habilita un espacio, el cual presenta un fogón y un pequeño altar, denominado Recinto-6 (R-6) y que constituye el espacio en donde se concentraría la mayor cantidad de personas durante las ceremonias que en este módulo se realizaban.

Si bien en el Recinto-6, con fogón central y altar, se estarían concentrando una mayor cantidad de personas, es el Recinto-1, también con fogón central, el que guardaría mayor importancia por realizarse allí una ceremonia de carácter privado con la participación de un grupo social bastante reducido, tal vez de mayor rango que aquellas que estarían participando en las actividades del Recinto-6.

\section{- FASE VII (Lámina 12)}

Se infiere que durante esta fase la actividad ceremonial decae y los recintos se convierten en espacios simplemente de concentración de grupos de personas.

Los fogones tanto del Recinto-1 (Foto 8) como del Recinto- 6 fueron sellados; al igual que el vano de acceso entre el Recinto- 1 y el Recinto-2, fue sellado por un muro de piedra de $1,20 \mathrm{~m}$ de longitud y una altura de $45 \mathrm{~cm}$.

La quema en algunas partes de los pisos permite inferir la posibilidad de que se haya estado preparando o cocinando (en menor medida) algunos alimentos.

El Recinto-1 tan sólo tiene comunicación directa con el R-3 y el R-4. Es en este Recinto-1 donde también se hallan pequeñas huellas de quema sobre el piso, lo que sumado a su configuración arquitectónica constituye indicadores sugerentes de una probable función habitacional/doméstica.

\section{- FASE VIII}

Corresponde al momento en que se produce el enterramiento de las estructuras para dar paso a la construcción de grandes plataformas elaboradas con muros de contención perimétricos.

El enterramiento que se produce sobre el espacio comprendido entre el R-1 y parte del R-3 habría tenido un carácter especial:

Primero, se colocó sobre el fogón sellado una cantidad considerable de argamasa de

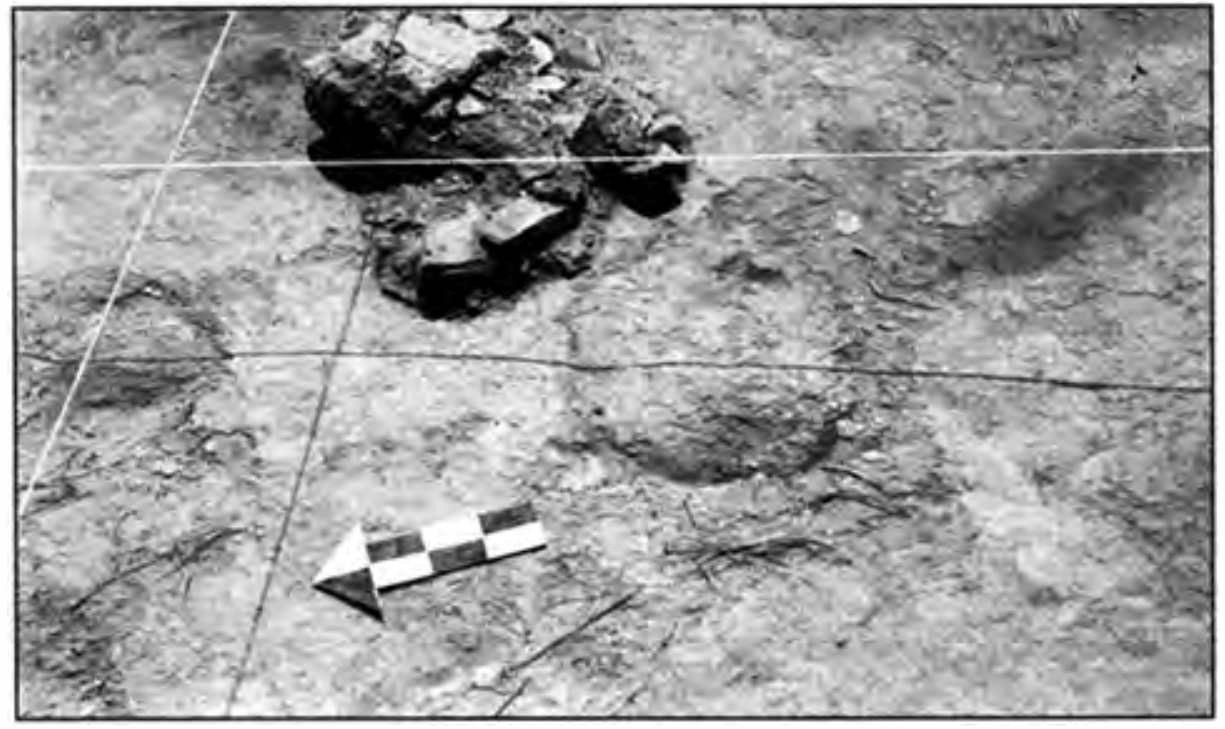

Foto 8. Detalle del fogón sellado sobre el Piso-I del Recinto-1. Se obsenvan, en la parte posterior, restos de la argamasa que cubría el fogón. 


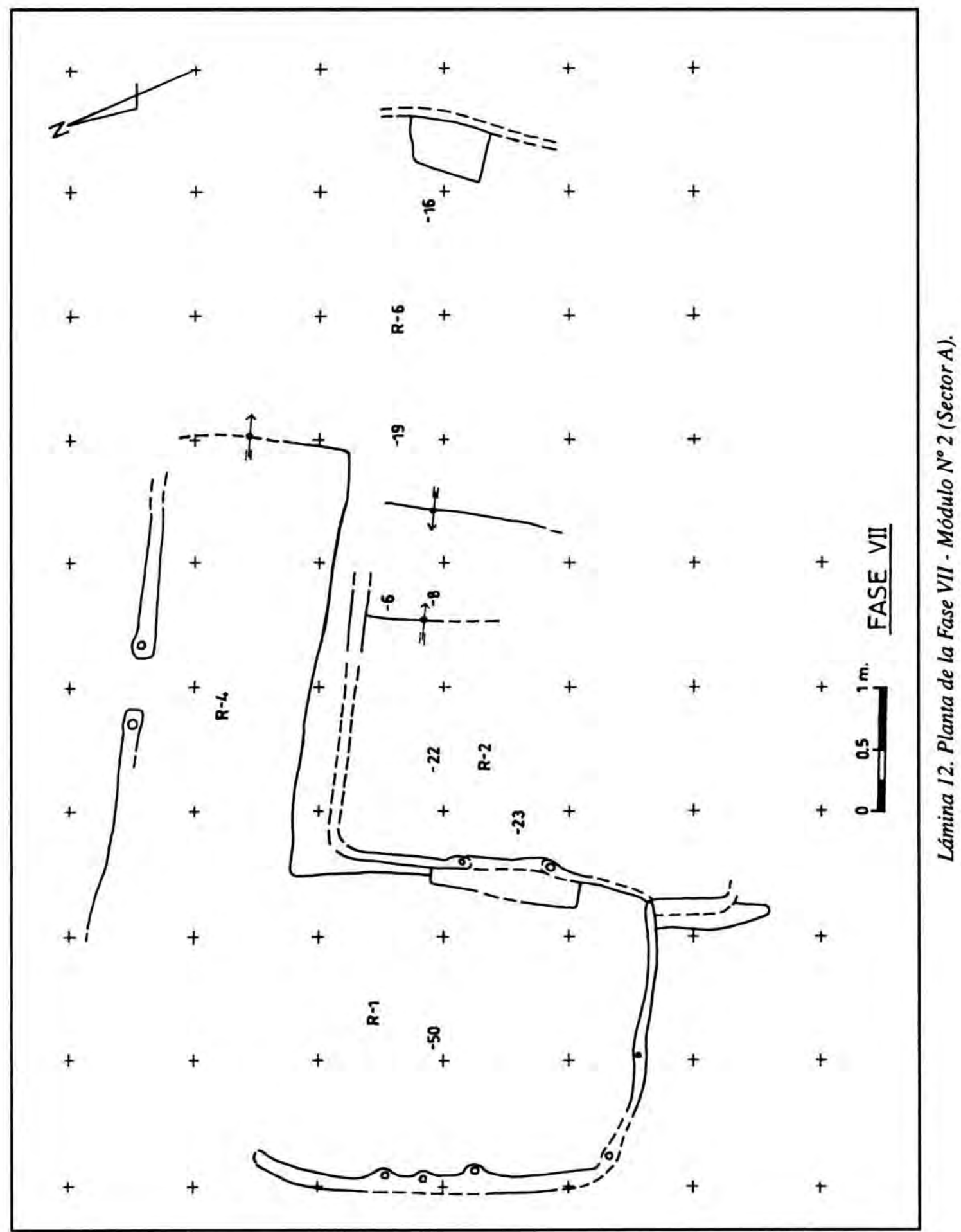


color gris claro; se observa, además, un bloque de argamasa amarillenta (de 18 por 17 por $12 \mathrm{~cm}$ ), guijarros casi medianos quemados y algunos sin quemar.

Segundo, cerca de la argamasa que cubre el fogón se colocó sobre el piso (P-1) una bolsa o red, la cual presentaba plumas amarillas sujetadas con hilos muy delgados; además, había hojas de "pacae", vértebras de "anchoveta" y "sardina", y fragmentos de "mate" asociados. Todo ello cubierto por una piedra angulosa (de 26 por 17 por $11 \mathrm{~cm}$ ).

Tercero, se cubrió buena parte del piso con una capa de ceniza (capa V), la cual alcanzaba un espesor de hasta $6 \mathrm{~cm}$, que contenía fragmentos de carbón muy pequeños y material orgánico (fragmentos de "mate", "choros", semillas de "algodón" y vértebras de "sardina").

Cuarto, se colocaron "manojos" de "sauce" asociados en conjuntos sobre la ceniza; estos conjuntos a su vez estaban circundados por piedras angulosas de tamaño mediano, algunas con pigmento rojo. En algunos conjuntos se hallaron, asociados, artefactos líticos, porciones de "paja", fragmentos de cuarzo, etc.

Y quinto, sobre todo lo descrito anteriormente se dispuso de 46 "shicras" (bolsas de contención elaboradas con fibra vegetal, las cuales contienen piedras al interior), de las cuales 10 contenían solo cantos rodados y estaban ubicadas hacia el norte, 8 contenían entre cantos rodados y piedras angulosas (principalmente granodiorita) y fueron colocadas en la parte central y 28 "shicras" contenían principalmente rocas de granodiorita, las que fueron depositadas en el lado sur del Recinto-1.

Luego todos los recintos fueron cubiertos con un relleno de tierra y piedras (capa IV), el cual contenía desechos de moluscos (prin- cipalmente "choros morados"). Todo ello constituiría el relleno constructivo con el que se edificarían finalmente las plataformas, las cuales han sido hechas con grandes bloques de piedra, que podrían alcanzar alturas de hasta $65-75 \mathrm{~cm}$. Dichos muros eran elaborados con piedras de $35-40$ $\mathrm{cm}$ aproximadamente de altura y $20 \mathrm{~cm}$ de espesor, unidas con argamasa de color gris oscuro, la cual presenta inclusiones de "grama". Cabe señalar que se ha observado al interior de los rellenos (capa IV) ubicados en las periferias del Módulo Arquitectónico $\mathrm{N}^{\circ} 2$, una mayor presencia de "choros morados", lo cual indicaría un cambio climático en relación con las fases anteriores, en los que se combina la presencia de "choros" y "machas".

\section{INTERPRETACIONES}

\section{DE LA DIVERSIFICACIÓN dE LAS FUNCIONES}

Los indicadores muestran una actividad ligada al consumo de alimentos, así como también recintos habitacionales, pero junto con ello hubo espacios en donde se realizaron acciones de culto, dentro de formalidades rituales que habrían desembocado, con el paso del tiempo, en una complejización que también se observa, aunque de carácter mayor, en los templos.

\section{DE LA ARQUITECTURA COMO RE- FLEJO DE LA RELIGIÓN}

Aquellos templos que son estructuras monumentales y las edificaciones no топиmentales, como la investigada, son construcciones que reflejan un nivel de explotación de la clase dominante con uso de la religión como instrumento ideológico de coerción. 
$\mathrm{Al}$ respecto, Bate (1984: 79) explica que "con el desarrollo de la explotación clasista, se origina y desarrolla igualmente la religión como concepción del mundo que [...] refleja la nueva situación social, convirtiéndose en instrumento ideológico de dominación: los sacerdotes que ofician los ritos son [...] los representantes de los dioses ante las comunidades, e intercambian con éstas productos materiales y fuerza de trabajo por servicios "espirituales"”.

En general, se debe indicar que en Caral existe un marcado uso diferenciado del espacio, en donde se construyeron grandes estructuras de carácter público, templos y residencias, pues son éstas una clara expresión física de uno de los centros más importantes del surgimiento de la ciudad en los Andes Centrales.

En el valle de Supe todo hace indicar, tal como lo plantea Shady y otros (2000: 14), que existió una integración cultural, en la que se habría formado un Estado Prístino con un gobierno unificado, cuya población habría construido un conjunto de centros urbanos, enmarcado dentro de lo que quizá fue el proceso más temprano de complejización social en los Andes Centrales.

\section{DE LAS "OFRENDAS"}

Las "ofrendas" pueden ser individuales ("manojos" de "sauce", de "molle", textiles quemados con o sin "armazón" de pequeñas ramas delgadas, etc.) o múltiples (hallados en hoyos, que contenían diversos elementos, como por ejemplo, "apelmazados" de vegetales, grandes "choros morados", "mates", esteras, etc.).

Además, se observa otros elementos o materiales que también fueron colocados durante el enterramiento y consecuente remodelación de las estructuras; ellos pueden ser: ceniza, textiles, "shicras", etc.

Todo lo cual constituye una serie de indicadores de un trasfondo ideológico; producto de la cosmovisión de la sociedad de Caral, plasmado principalmente durante el proceso constructivo de las edificaciones, hayan o no cumplido éstas una función ceremonial/ritual.

En lo que respecta a los "mechones" de cabello, tales como los hallados en la capa IX del Recinto-1, se sabe que han sido reportados en pocos yacimientos del Arcaico Tardío: Wendt (1964: 21) menciona que en Río Seco de León, "...se hallaron con cierta frecuencia...”; en Los Gavilanes, Bonavía los halló en el Hoyo 1, y envueltos por un tejido los halló en la boca del Hoyo 4 y de igual forma en el Hoyo 7; también los halló en el edificio público, entre el relleno pero muy cerca del piso y sobre el piso, asociado al fogón central. Bonavía (1982: 271) considera que "es posible, como dice Feldman, que sean ofrendas propiciatorias o consagratorias que en el caso de Los Gavilanes están asociadas a edificios de interés público, pero que en Áspero parecerían estar vinculadas también a estructuras profanas".

Lo cierto es que los "mechones" de cabello están presentes tanto en estructuras residenciales como en estructuras dedicadas a actividades rituales o ceremoniales; por otro lado, cualquiera que sea la asociación a otro material (textiles, etc.) con el cual se haya depositado, estos "mechones" debieron tener un significado aún no muy claro.

\section{DE LAS "SHICRAS"}

En principio, el término "shicra" ha sido recogido del diccionario quechua del Huallaga: Rimaycuna-Quechua de Huánuco 
(1998), en el cual tiene el siguiente significado: "Bolsa o canasta tejida de fibra de maguey". Si bien, es el "junco" (Schoenoplectus sp.) y la Cortaderia sp., las fibras vegetales utilizadas principalmente en la manufactura y no el "maguey", igualmente sigue siendo "shicra" uno de los términos quechuas que más se acerca a la definición de este tipo de tejidos.

Otros investigadores han optado por dar otras denominaciones, como por ejemplo Bonavía (1982), quien las denomina bolsas de contención; Quilter (1985; 1991), las denomina indistintamente sacos de fibra, canastas, o shicras; Engel (1967), canastas de carga, etc.

Debemos señalar que en la Costa Norcentral, el reporte más detallado es el realizado por Bonavía (1982: 132-138; 2000: 84) en Los Gavilanes, aproximadamente a 26 $\mathrm{km}$ al norte del valle de Huarmey, donde "bolsas de contención" fueron halladas en "un pequeño edificio público que estuvo techado y en cuyo centro había un fogón" (Bonavía, 2000: 86). Dicha estructura fue construida hacia los 2500 años a. C., al mismo tiempo que el sitio fue convertido en un lugar para almacenar maíz.

Y en el valle de Supe, su presencia fue reportada por primera vez por R. Feldman, en el asentamiento de Áspero, quien indicó que "en las pirámides... se introdujo una innovación en el relleno de los cuartos superiores. Consistía en grandes bolsas confeccionadas de 'gramíneas' y 'juncos' (Cyperus sp., Typha sp.)" (Feldman 1980, Fung 1999: 179).
La Cortaderia sp. constituyó una materia prima vegetal flexible, y es probable que aquellas "shicras" elaboradas a base de esta fibra, y que han sido reportadas en la presente investigación, pertenezcan a la especie jubata. Lamentablemente la Cortaderia $s p$. no ha sido reportada en yacimientos del Arcaico con relación a la manufactura de "shicras"; se sabe que su uso se ha dado en otras regiones de América, como por ejemplo el dato recogido por la arqueóloga argentina Cecilia Pérez de Micou (2001), quien a partir de un estudio sobre tecnologías cesteras sobre la base de una colección que provino de la localidad de Doncellas, ubicada en la puna de Jujuy, al noroeste de Argentina, identifica en la cestería un uso especializado de algunas partes de la Cortaderia sp., vegetal que, según menciona, crece localmente.

En la estructura excavada en el Sector A de Caral, se ha podido observar que las "shicras" fueron colocadas en lugares escogidos especialmente, los cuales han tenido una relación directa con la edificación, sellado o destrucción de un elemento arquitectónico.

De esta forma, la "shicra" habría estado elaborada con el peso y las dimensiones apropiadas, conforme a lo requerido en relación directa a la capacidad de carga y resistencia de la persona que la confeccionó, siendo al parecer, una labor realizada más de una vez por cada persona, dentro del proceso de construcción de alguna estructura destinada al culto, dada la recurrencia en las variables tecnológicas (peso, dimensiones, tipo y tamaños de los guijarros, tipo de fibra vegetal de la estructura principal de las "shicras", etc.). 


\section{CONCLUSIONES}

1.- La arquitectura definida hasta el momento, en la presente investigación, muestra una combinación de técnicas constructivas.

2.- Existió una actividad ceremonial/ritual al interior del conjunto arquitectónico, pero ésta no siempre se mantuvo con la misma intensidad, e incluso los recintos cambiaron de uso durante algunas fases, diversificándose la función entre lo ceremonial/ritual y lo habitacional.

3.- Se infiere que hubo actos rituales durante y después de las remodelaciones, evi- denciados por la presencia de ofrendas dejadas al interior de los rellenos constructivos.

4.- Las "ofrendas" pueden ser individuales o múltiples, además de otros elementos o materiales que también fueron colocados durante el enterramiento y consecuente remodelación de las estructuras.

5.- La utilización de las "shicras" sería el reflejo, plasmado en una expresión artesanal, de una porción de la cosmovisión de la sociedad que las empleó. 


\section{BIBLIOGRAFÍA}

BATE, Luis Felipe

1984 "Hipótesis sobre la sociedad clasista inicial": 47-86. En Boletín de Antropología Americana. $\mathrm{N}^{\circ} 9$, julio. Instituto Panamericano de Geografía e Historia. México, D. F.

BONAVÍA, Duccio

1982 Los Gavilanes: mar desierto y oasis en la historia del hombre (612 páginas). COFIDE e Instituto Arqueológico Alemán. Lima.

2000 "Almacenamiento en arena: Una vieja técnica que se ha perdido": 84-92. En Revista ARKINKA. N ${ }^{\circ} 59$. Octubre. Año 5. Lima.

\section{ENGEL, Frederic}

1967 "El complejo El Paraíso en el valle del Chillón, habitado hace 3500 años; nuevos aspectos de la civilización de los agricultores del pallar".: 241-280. En Separata de Anales Científicos de la Universidad Agraria. Vol. V. julio-diciembre. $\mathrm{N}^{\circ} 3-4$. Lima. Perú.

FELDMAN, Robert 1980 Aspero, Perú. Architecture, subsistence, economy, and other artifacts of a preceramic maritime chiefdom. Harvard University. Cambridge, Massachusetts.

\section{FUNG, Rosa}

1999 "El proceso de neolitización en los Andes Tropicales".: 141-196. En Historia de América Latina. Volumen I. Las Sociedades Indígenas. Editor: Luis. G. Lumbreras. Universidad Andina Simón Bolívar. LIGRESA. Quito.

\section{PÉREZ DE MICOU, Cecilia}

2001 "Tecnología cestera en la colección Doncellas (Jujuy, Argentina)". En Boletín del Museo de Arqueología y Antropología. Centro Cultural de la Universidad Nacional Mayor de San Marcos. Año 4, $\mathrm{N}^{\circ} 1$. Lima.

\section{QUILTER, Jeffrey}

1985 "Architecture and chronology at El Paraíso, Perú”. 279-297. En Journal of Field Archaeology. Vol. 12. Ripon, Wisconsin.

1991 "Late Preceramic Perú". 387-438. En Journal of World Prehistory. Vol. 5, $\mathrm{N}^{\circ} 4$. Plenum Publishing Corporation.

\section{SHADY, Ruth}

1997 La Ciudad Sagrada de Caral - Supe en los Albores de la Civilización en el Perú (75 páginas). Fondo Editorial. Universidad Nacional Mayor de San Marcos. Lima.

SHADY, Ruth; LÓPEZ, Sonia

1999 "Ritual de enterramiento de un recinto en el Sector Residencial A en CaralSupe". En Boletín de Arqueología PUCP, $N^{\circ}$ 3. Peter Kaulicke, Editor. Fondo Editorial PUCP, 2000, Lima.

SHADY, Ruth; DOLORIER, Camilo; MONTESINOS, Fanny y CASAS, Lyda 2000 "Los orígenes de la civilización en el Perú. El área norcentral y el valle de Supe durante el Arcaico Tardío": 13-48. En Arqueología y Sociedad $\mathrm{N}^{\circ} 13$. Museo de Arqueología y Antropología de la Universidad Nacional Mayor de San Marcos. Lima.

WENDT, W. E.

1964 "Die Präkeramische Siedlung am Río Seco, Peru": 225-275. Baessler Archiv, Neve Folge, Band IX. "El asentamiento precerámico en Río Seco, Perú": 1-50. Traducción de Peter Kaulicke. Revisado por Rosa Fung Pineda y Atilio Corzo Stagnaro. 


\section{ANEXO 1}

Principales materiales orgánicos identificados en las diferentes capas estratigráficas.

\begin{tabular}{|l|l|}
\hline \multicolumn{2}{|c|}{ MATERIAL VEGETAL } \\
\hline \multicolumn{1}{|c|}{ Nombre común } & \multicolumn{1}{c|}{ Taxa } \\
\hline Mate & Lagenaria siceraria \\
\hline Algodón & Gossypium barbadense \\
\hline Pacae & Inga feuillei \\
\hline Sauce & Salix humboldtiana \\
\hline Junco & Shoenoplectus sp. \\
\hline Caña brava & Gynerium sagittatum \\
\hline Molle & Schinus molle \\
\hline Huarango & Prosopis sp. \\
\hline Carricillo & Phragmites australis \\
\hline Grama & Fam. Poaceae \\
\hline
\end{tabular}

\begin{tabular}{|l|c|}
\hline \multicolumn{2}{|c|}{ MATERIAL ANIMAL } \\
\hline Nombre común & Taxa \\
\hline Rata silvestre & Muridae indeterminado \\
\hline
\end{tabular}

\begin{tabular}{|l|l|}
\hline \multicolumn{2}{|c|}{ MATERIAL ICTIOLÓGICO } \\
\hline \multicolumn{1}{|c|}{ Nombre común } & \multicolumn{1}{c|}{ Taxa } \\
\hline Anchoveta & Engraulis ringens \\
\hline Sardina & Sardinops sagax \\
\hline
\end{tabular}

\begin{tabular}{|l|l|}
\hline \multicolumn{2}{|c|}{ MATERIAL MALACOLÓGICO } \\
\hline \multicolumn{1}{|c|}{ Nombre común } & \multicolumn{1}{c|}{ Taxa } \\
\hline Macha & Mesodesma donacium \\
\hline $\begin{array}{l}\text { Choro zapato o choro } \\
\text { morado }\end{array}$ & Choromytilus chorus \\
\hline
\end{tabular}




\section{ANEXO 2}

Dimensiones, peso y materia prima vegetal empleada en la elaboración de las "shicras".

\begin{tabular}{|c|c|c|c|c|c|c|}
\hline \multirow{2}{*}{ "SHICRA" } & \multicolumn{2}{|r|}{ 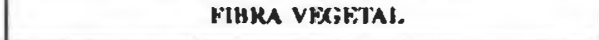 } & \multicolumn{4}{|c|}{ DIMENSIONFS (cm) } \\
\hline & $\begin{array}{l}\text { FSTKUCTURA } \\
\text { PRINCIPAL }\end{array}$ & ESTRUCTIRA COMPLEMENTARL & NORTESUR & ESTE-OESTE & ESPESOR & 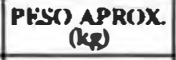 \\
\hline$\$ 6$ & Contuderiatsp. & $\ldots$ & 28 & 33 & 23 & $1,3.00$ \\
\hline 57 & Conuderia sp. & $\cdots$ & 36 & 35 & 17 & 18.50 \\
\hline 58 & Conaderia sp. & -- & 39 & 28 & 14 & 13.50 \\
\hline 59 & Conuderia $s p$. & $\ldots .$. & 26 & 37 & 16 & 13.00 \\
\hline$(x)$ & Contuderia sp. & $-\cdots$ & 46 & 45 & 14 & 28.75 \\
\hline 61 & Conaderia $x p$. & $\cdots$ & 34 & 37 & 21 & 22.10 \\
\hline 62 & Conaderia sp. & $\cdots$ & 24 & 23 & 14 & 6.50 \\
\hline 6.3 & Conaderia sp. & $\ldots$ & 30 & 33 & 16 & 13,00 \\
\hline 64 & Coniuderin sp. & -- & 35 & 32 & 11 & 14.00 \\
\hline 6.5 & Conaderia sp. & $\ldots$ & 36 & 3.5 & 17 & 16,50 \\
\hline $6 x$ & Contuderia sp. & $\cdots$ & 35 & 34 & 11 & 17,50 \\
\hline 67 & Contaderia sp. & $\cdots$ & 36 & 34 & 15 & 15.00 \\
\hline 68 & Contuderiusp. & $\ldots$ & 30 & 29 & 17 & 20.00 \\
\hline 6) & Comaderia sp. & $\ldots$ & 32 & 33 & 21 & 17.50 \\
\hline 7) & Compaderia sp. & $\ldots$ & 36 & 24 & 16 & 15,10 \\
\hline 71 & Comaderin sp. & $\ldots$ & 37 & 40 & 17 & 14.00 \\
\hline 72 & Corruderia $x p$. & $-\infty$ & 34 & 19 & 23 & 15,50 \\
\hline 73 & Concuderias.sp. & $-\infty$ & 35 & 30 & 19 & 10.7. \\
\hline 74 & Connaderia .pp. & Soguilta de "junco" (Shoencplectus sp.) & 30 & 35 & 20 & 13.75 \\
\hline 75 & Conaderia sp. & -- & 28 & 26 & 12 & 10.00 \\
\hline 76 & Concuderia sp. & Soguilla de "jumers" (Shueneplectus sp.) & 36 & 14 & 16 & 8,00 \\
\hline$\pi$ & Confuderia sp. & $\ldots$ & 2.5 & 34 & 17 & 13.00 \\
\hline $7 x$ & Conculeria sp. & Soguilla de "junco" (Shnensplectus sp.) & 30 & 24 & 19) & 10.00 \\
\hline 79 & Consuderiasp. & Suguilla ke "juncu" (Shoenoplectus sp.) & 35 & 34 & 25 & 18.50 \\
\hline$(8)$ & Concuderia sp. & Singuilla de "juncto" (Shoenoplectus sp.) & 30 & 34 & 19) & 21.00 \\
\hline 81 & Contaderia sp. & $\cdots$ & 33 & 30 & 22 & 14.00 \\
\hline 82 & Conuderia sp. & -- & 35 & 31 & 11 & 18.25 \\
\hline 83 & Connuderia sp. & $\ldots$ & 34 & 29) & 12 & $16,(0)$ \\
\hline$\$ 4$ & Consaderia sp. & $\cdots$ & 20 & 24 & 15 & 5.25 \\
\hline 85 & Contuleria sp. & $\cdots$ & 3.0 & 28 & 20 & 13.25 \\
\hline 86 & Conaderier $x p$. & Singuilla de "jurxa" (Shoenoplectur..p.) & 27 & 41 & 25 & $I X .(x)$ \\
\hline 87 & Conaderia sp. & $-\cdots$ & 35 & 26 & 19) & $15,(x)$ \\
\hline 88 & Conaderin .sp. & Suguilla de "junev" (Shoenerplectus sp.) & 33 & 29 & 18 & $19,7.5$ \\
\hline (8) & Conaderias sp. & Singuilla de "jurxu" (Sherenouplectus sp.) & 29) & 40) & 13 & 13.25 \\
\hline 90 & Conuderin sp. & $\cdots$ & 28 & 24 & 15 & 14.(X) \\
\hline 91 & Conaderia.$p$. & Soguilla de "juncon" (Shinenoplectus sp.) & 39 & 33 & 22 & 13.00 \\
\hline 92 & Conculeriusp. & & 35 & 32 & IX & 9.75 \\
\hline 93 & Conuderia sp. & Suguilly de "junow" (Shoenoplectous sp.) & 26 & 35 & 15 & 8,25 \\
\hline 24 & Connuleriasp. & $\ldots$ & 22 & 20 & 11 & 3.50 \\
\hline 95 & Conaderia sp. & $\cdots$ & 30 & 36 & 24 & 16,25 \\
\hline$x$ & Connaderia sp. & $\cdots$ & 34 & 29 & 25 & $17 .(x)$ \\
\hline 97 & Conaderin sp. & Soguilla de "junco" (Shoenoplecius sp.) & 30 & 31 & 16 & 1450 \\
\hline 98 & Connderiat.sp. & $\ldots$ & 29 & 30 & 18 & 12.75 \\
\hline 49 & Contuderiasp. & Sirguilla ck "junas" (Shorensplectus .sp.) & 30 & 25 & 22 & 10.00 \\
\hline 100 & Conaderia sp. & Soguilla de "juncx)" (Shosennplectus .sp.) & 36 & 33 & 14 & 16.50 \\
\hline 101 & Corinderia sp. & -- & 29 & 35 & 19) & 12,50 \\
\hline
\end{tabular}

